\title{
Evidence and consensus recommendations for the pharmacological management of pain in India
}

This article was published in the following Dove Press journal:

Journal of Pain Research

29 March 2017

Number of times this article has been viewed

\section{Gur Prasad Dureja' \\ Rajagopalan N lyer ${ }^{2}$ \\ Gautam Das ${ }^{3}$ \\ Jaishid Ahdal ${ }^{4}$ \\ Prashant Narang ${ }^{4}$ \\ On behalf of the Pain \\ Working Group}

'Delhi Pain Management Centre, New Delhi, Delhi, ${ }^{2}$ Department of Orthopaedics, Raja Rajeswari Medical College and Hospital, Bengaluru, Karnataka, ${ }^{3}$ Daradia Pain Clinic, Kolkata, West Bengal, ${ }^{4}$ Department of Medical Affairs, Janssen India, Johnson \& Johnson Pvt Ltd, Mumbai, Maharashtra, India
Correspondence: Prashant Narang Department of Medical Affairs, Janssen India, Johnson \& Johnson Pvt Ltd, 50I Arena Space, Off Jogeshwari Vikhroli Link Road, Jogeshwari East, Mumbai, Maharashtra, India

$\mathrm{Tel}+9 \mid 98$ II646909

Email pnarangI@ITS.JNJ.com
Abstract: Despite enormous progress in the field of pain management over the recent years, pain continues to be a highly prevalent medical condition worldwide. In the developing countries, pain is often an undertreated and neglected aspect of treatment. Awareness issues and several misconceptions associated with the use of analgesics, fear of adverse events - particularly with opioids and surgical methods of analgesia - are major factors contributing to suboptimal treatment of pain. Untreated pain, as a consequence, is associated with disability, loss of income, unemployment and considerable mortality; besides contributing majorly to the economic burden on the society and the health care system in general. Available guidelines suggest that a strategic treatment approach may be helpful for physicians in managing pain in real-world settings. The aim of this manuscript is to propose treatment recommendations for the management of different types of pain, based on the available evidence. Evidence search was performed by using MEDLINE (by PubMed) and Cochrane databases. The types of articles included in this review were based on randomized control studies, case-control or cohort studies, prospective and retrospective studies, systematic reviews, meta-analyses, clinical practice guidelines and evidence-based consensus recommendations. Articles were reviewed by a multidisciplinary expert panel and recommendations were developed. A stepwise treatment algorithm-based approach based on a careful diagnosis and evaluation of the underlying disease, associated comorbidities and type/duration of pain is proposed to assist general practitioners, physicians and pain specialists in clinical decision making.

Keywords: clinical practice guidelines, consensus recommendations, expert opinion, pain management, treatment algorithm

\section{Introduction}

Pain, as defined by the International Association for the Study of Pain (IASP) is "an unpleasant sensory and emotional experience associated with actual or potential tissue damage, or described in terms of such damage". ${ }^{1}$ Pain can be experienced as an acute, chronic or intermittent sensation, or as a combination of the three, and is reported to be the common reason for medical visits. However, since pain has always been regarded as a symptom, not a disease state, ${ }^{2}$ there has been an enormous gap between prevalence and treatment, and it remains largely undertreated. ${ }^{3,4}$ Acute pain, the most commonly experienced type of pain, may be a result of injuries, acute illnesses, surgeries or labor. ${ }^{5}$ The overall prevalence of acute pain in hospital and ambulatory settings is reported to range between $30 \%$ and $80 \% .^{6-8}$ In addition to discomfort, uncontrolled acute pain translates to chronic pain, which may lead to delayed healing, prolonged hospitalization and increased morbidity. ${ }^{9}$ Globally, approximately $20 \%$ of adults suffer from pain, of 
which, $10 \%$ report persistent pain. ${ }^{10}$ Contrary to acute pain, chronic pain is seldom considered an individual entity, the focus majorly being on symptom relief. Chronic pain is generally associated with chronic illnesses such as neuropathy, cancer or human immunodeficiency virus infection-acquired immune deficiency syndrome (HIV-AIDS), and it is difficult to predict the nature and severity of pain. ${ }^{11}$ Several studies report a significantly high prevalence of chronic pain with certain neuropathic characteristics $(6 \%-10 \%)$, which is of higher severity and longer duration. ${ }^{12-14}$ Untreated chronic pain significantly affects the quality of life (QoL) of the patients, ${ }^{15}$ is associated with considerable mortality, ${ }^{16}$ and can be a major cause of absenteeism from work or reduced work performance as well as loss of productivity. ${ }^{17}$

In developed countries too, pain is a commonly reported medical problem and comes with immense personal costs and a huge societal health care burden; ${ }^{18,19}$ the cost of chronic pain in the US has been estimated at \$560-\$635 billion. ${ }^{19}$ It is, therefore, not surprising to note an uncharacteristically high prevalence of pain in a developing economy like India, which is already struggling with a growing disease burden and lack of quality health care resources. ${ }^{20}$ According to the Global Burden of Diseases (GBD) survey, low-back pain (LBP) and migraine were amongst the top five medical conditions resulting in years lived with disability in the Indian population in $2013 .{ }^{21}$ In India, around 100,000 patients with cancer or HIV-AIDS die every year due to inadequate pain treatment. ${ }^{22}$ A survey of chronic pain conducted across eight major cities in India highlighted a high point prevalence (13\%) of chronic pain, with $30 \%$ of the patients without treatment and $56 \%$ reporting unsatisfactory treatment. ${ }^{23}$

Currently, there is a need to develop treatment recommendations based on available evidence to guide Indian physicians in the management of pain.

\section{Unmet needs of India}

According to a survey by the World Health Organization (WHO), the incidence of chronic pain was demonstrated to range between $5 \%$ and $33 \%$ in 15 centers across Asia, Africa, Europe and the USA. ${ }^{10}$ India has a high burden of chronic diseases and injuries, which are the leading causes of disability and mortality and have pain as comorbidity. ${ }^{24,25}$ Globally, pain prevalence in the elderly population is high $^{26}$ and is further expected to rise, ${ }^{27,28}$ owing to the presence of multiple comorbidities ${ }^{29}$ and barriers related to communication and cognition. ${ }^{30}$ With a considerable increase in life expectancy in the past decade, India has witnessed an unprecedented rise in the ailing population, who are struggling to get adequate treatment for pain. ${ }^{31,32}$ Furthermore, there are some additional challenges, such as lack of adequate health care facilities, poverty, inadequate health care expenditure and lack of awareness among health care practitioners and patients. ${ }^{33}$ Health care centers in India are often not well equipped to provide adequate treatment for pain, with physicians relying mostly on over-the-counter analgesics. ${ }^{34,35}$ This generalized approach seldom works in most complex pain disorders, which require a detailed diagnosis and thoughtful, planned management. ${ }^{36}$ Another concern stemming from lack of awareness is the use of irrational and inappropriate multidrug prescriptions in India. Nonsteroidal anti-inflammatory drugs (NSAIDs) are the second most common components of prescriptions in India. ${ }^{37-39}$ Rampant polypharmacy, coupled with lack of awareness, has had a huge impact on analgesic efficacy and presents tolerability issues. ${ }^{40}$ Several misconceptions regarding use of analgesics and fear of adverse events associated with the use of opioids or surgical methods of analgesia result in suboptimal treatment of pain. ${ }^{41,42}$ These inadequacies might be overcome by the amalgamation of expert opinions and available evidence to form standardized treatment guidelines for pain therapy. Hence, an expert panel was convened to delve on these lacunae and frame an appropriate treatment paradigm for pain management. The objective of this publication is to summarize the evidencebased consensus recommendations of this expert panel for the pharmacological management of pain in India.

\section{Methodology}

Literature search of the current evidence was performed using the MEDLINE (by PubMed) and Cochrane databases. The articles included randomized control studies, case-control or cohort studies, prospective and retrospective studies, systematic reviews, meta-analyses, clinical practice guidelines and evidence-based consensus recommendations. Evidence grading was performed as per the following criteria used by the National Guidelines Clearinghouse: ${ }^{43}$

Level 1: evidence from randomized control studies, systematic reviews and meta-analyses

Level 2: evidence from nonrandomized, prospective or retrospective studies

Level 3: evidence from comparative, case-control and descriptive studies

Level 4: expert committee reports or clinical opinions of respected authorities 
A multidisciplinary expert panel, composed of pain specialists, orthopedic surgeons, gastroenterologists, cardiologists, neurologists and nephrologists, with clinical and research expertise in the diagnosis and treatment of pain was convened, and recommendations were formulated based on expert opinions and available evidence. Based on the level of evidence, recommendations were graded as follows:

Grade A: based on evidence Level 1

Grade B: based on evidence Level 2 or extrapolated from Level 1

Grade C: based on evidence Level 3 or extrapolated from Level 1 and 2
Grade D: based on evidence Level 4 or extrapolated from

\section{Levels 1-3}

Recommendation statements were developed, circulated among panel members and modified based on their feedback until unified consensus was achieved.

\section{Types of pain}

Several methods of classification of pain have been developed to assist the physician in the appropriate diagnosis and treatment of pain in routine clinical practice. Pain can be classified into different types on the basis of duration or intensity, pathological mechanism and anatomic location (Table 1).

Table I Different types of pain

\begin{tabular}{|c|c|c|c|}
\hline Type & Pathophysiology & Characteristics & Examples \\
\hline \multicolumn{4}{|c|}{ Based on underlying pathophysiology } \\
\hline Nociceptive pain & $\begin{array}{l}\text { Activation of nociceptors in response to } \\
\text { noxious stimuli }\end{array}$ & $\begin{array}{l}\text { Sharp, burning pain (somatic) or dull, } \\
\text { aching pain (visceral) }\end{array}$ & $\begin{array}{l}\text { Back pain, headaches, neck pain, shoulder } \\
\text { pain, pain due to burns and injuries }\end{array}$ \\
\hline Neuropathic pain & $\begin{array}{l}\text { Central sensitization or neuronal } \\
\text { damage }\end{array}$ & $\begin{array}{l}\text { Severe, burning, shooting or numbing } \\
\text { pain, increased sensitivity to stimuli } \\
\text { (hyperalgesia and allodynia) }\end{array}$ & $\begin{array}{l}\text { Peripheral neuropathy, diabetic } \\
\text { neuropathy, trigeminal neuralgia, } \\
\text { complex regional pain syndrome (CRPS), } \\
\text { neuropathic pain due to spinal injury }\end{array}$ \\
\hline Mixed pain & Nociceptive and neuropathic origin & $\begin{array}{l}\text { Severe, shooting pain or dull, aching pain } \\
\text { or pain with mixed characteristics }\end{array}$ & LBP with radiculopathy, cancer pain \\
\hline \multicolumn{4}{|c|}{ Based on duration } \\
\hline Acute pain & $\begin{array}{l}\text { Activation of peripheral nociceptors, } \\
\text { accompanied by release of COX } \\
\text { enzymes and prostaglandins }\end{array}$ & $\begin{array}{l}\text { Lasts from few seconds to less than } \\
6 \text { months }\end{array}$ & $\begin{array}{l}\text { Injuries, headaches, sprains, postoperative } \\
\text { pain, back pain }\end{array}$ \\
\hline Chronic pain & $\begin{array}{l}\text { Sensitization at the level of spinal } \\
\text { neurons via multiple mechanisms }\end{array}$ & Lasts for $\geq 6$ months & $\begin{array}{l}\text { Chronic primary pain, cancer pain, } \\
\text { posttraumatic and postsurgical pain, } \\
\text { neuropathic pain, headache and orofacial } \\
\text { pain, visceral pain, musculoskeletal pain }\end{array}$ \\
\hline Breakthrough pain & $\begin{array}{l}\text { Pain in a well-treated patient due to } \\
\text { movement (incidental), spontaneous or } \\
\text { resulting from weaning off of drugs or } \\
\text { effect of drug }\end{array}$ & Lasts from few seconds to hours & Cancer pain \\
\hline \multicolumn{4}{|c|}{ Based on etiology } \\
\hline Cancer pain & $\begin{array}{l}\text { Caused due to cancer itself (brain } \\
\text { tumors, breast cancer), drug treatment } \\
\text { (chemotherapy, radiation) or associated } \\
\text { disease (neuropathy) }\end{array}$ & $\begin{array}{l}\text { Acute or chronic pain of mild, moderate } \\
\text { or severe intensity with/without } \\
\text { breakthrough pain }\end{array}$ & All types of cancers \\
\hline CNCP & May have multiple etiologies & $\begin{array}{l}\text { Moderate-to-severe pain with/without } \\
\text { restricted mobility }\end{array}$ & Rheumatoid arthritis, osteoarthritis \\
\hline \multicolumn{4}{|l|}{ Based on location } \\
\hline LBP & $\begin{array}{l}\text { Caused due to bad posture, strains/ } \\
\text { sprains, underlying disease (malignancy } \\
\text { or infection) or referred pain (kidney or } \\
\text { gall stones) }\end{array}$ & $\begin{array}{l}\text { Mild and moderate-to-severe pain } \\
\text { with/without impaired movement or } \\
\text { physical function }\end{array}$ & Acute LBP, herniated disk, spondylosis \\
\hline $\begin{array}{l}\text { Neck pain and } \\
\text { shoulder pain }\end{array}$ & $\begin{array}{l}\text { Caused due to strains, sprains, incorrect } \\
\text { posture and compression of spinal cord } \\
\text { or injuries }\end{array}$ & $\begin{array}{l}\text { Mild and moderate-to-severe pain } \\
\text { with/without impaired movement or } \\
\text { physical function }\end{array}$ & Axial neck pain, cervical radiculopathy \\
\hline Headaches & $\begin{array}{l}\text { Caused due to incorrect posture, stress, } \\
\text { migraine or underlying disease (tumors) }\end{array}$ & $\begin{array}{l}\text { Headache associated with migraine may } \\
\text { present additional symptoms (aura), } \\
\text { visual problems or vertigo }\end{array}$ & $\begin{array}{l}\text { Tension-type headaches, migraine } \\
\text { headaches }\end{array}$ \\
\hline Referred pain & $\begin{array}{l}\text { Type of visceral pain that radiates to } \\
\text { surrounding regions }\end{array}$ & $\begin{array}{l}\text { May be sharp, pulsating pain or dull, } \\
\text { aching pain depending upon the origin }\end{array}$ & $\begin{array}{l}\text { Angina (jaws and shoulders), stones } \\
\text { (abdomen and back) }\end{array}$ \\
\hline
\end{tabular}

Abbreviations: CNCP, chronic noncancer pain; COX, cyclooxygenase; LBP, low-back pain. 


\section{Based on underlying pathophysiology} Nociceptive pain

Nociceptive pain is elicited through $\mathrm{A}, \delta$ and $\mathrm{C}$ nociceptive receptors present in peripheral tissues, which are activated by chemical, mechanical or thermal stimuli. ${ }^{44}$ These receptors play an important role in the regulation of natural defense mechanisms and elicit pain as a response to potential tissue damage. A number of chemical substances aggravate the nociceptive response to pain; the most common ones are bradykinin, histamine, serotonin and prostaglandins (cyclooxygenase [COX] 1 and 2).

\section{Neuropathic pain}

Neuropathic pain primarily refers to pain initiated or caused by a primary lesion or damage to the central nervous system and includes disorders such as peripheral neuropathy, diabetic neuropathy, postherpetic neuralgia, trigeminal neuralgia, causalgia and certain types of cancer pain. ${ }^{45,46}$ The pathways attributed to the generation of neuropathic pain involve abnormal excitability of afferent neurons, central sensitization following peripheral activation of neurons, loss of primary afferent response and activation of proinflammatory cytokines..$^{47,48}$ Each of these factors may correspond to a particular mechanistic pathway, causing differences in the pattern and intensity of the somatosensory response. .9,50 $^{4}$

\section{Mixed pain}

In certain cases, pain may result from a combination of nociceptive and neuropathic processes. ${ }^{51}$ This type of pain is considered as the mixed type and is most frequently experienced by patients with cancer and those with some complex neuropathies. ${ }^{52-54}$

\section{Based on duration}

\section{Acute pain}

Acute pain is caused due to an existing disease or injury, usually lasting for hours, days or months or until the disease or injury is healed. ${ }^{55}$ This type of pain has a certain identifiable biological origin and is predictable in nature. ${ }^{56}$ Acute pain is a part of the normal biological defense against a potential threat or injury and is accompanied by protective reflexes. ${ }^{57}$ The sources of acute pain could be an acute illness (eg, appendicitis), perioperative (pain due to existing disease and surgical procedure), major trauma (vehicle accident), burns or due to childbirth.

\section{Chronic pain}

Chronic pain persists even after the healing of the disease or injury and may be physically and emotionally distressing. Often, there is no single biological point of origin for this pain, resulting in a complex pathophysiology that necessitates the use of multiple therapeutic interventional strategies for alleviation..$^{58}$ This type of pain may be a result of an existing chronic disorder (examples are cancer or noncancer pain such as HIV-AIDS, rheumatoid arthritis and LBP) or may have no known cause (idiopathic pain). Moreover, some secondary causes may include increased sensitivity to external stimuli (hyperalgesia) or pain due to innocuous stimuli (allodynia). ${ }^{59}$

\section{Breakthrough pain}

Breakthrough pain is defined as transient flare-ups of severe and uncontrolled pain, in adequately controlled pain settings. ${ }^{60}$ These episodic exacerbations of pain are characteristically observed in patients with cancer and last usually from a few seconds to hours. Breakthrough pain may be idiopathic (without known cause), incidental and associated with a precipitating factor (eg, movement), or may be experienced in the interim between two doses. ${ }^{61}$

\section{Based on etiology}

\section{Cancer pain}

Pain is the most common symptom experienced by patients with cancer. The origin of cancer pain may be nociceptive (somatic or visceral) when there are changes in the underlying tissue pathology and neuropathic, when there is an involvement of neuronal damage. The severity of cancer pain increases as the disease progresses, with patients in the metastatic stage reporting the most severe pain. ${ }^{62}$ Cancer pain may be felt at the site of tumor or may be referred to a secondary region of the body. ${ }^{63}$ Breakthrough pain is another feature of cancer pain, which may be a consequence of repeated nociceptive sprouting or synaptic changes at the spinal dorsal horn (DH) ${ }^{64}$ Optimization of opioid therapy may be useful in preventing episodic exacerbations at the end of dose. ${ }^{65}$

\section{Noncancer pain}

Chronic pain due to nonmalignant causes is referred to as chronic noncancer pain (CNCP). Unlike cancer pain, CNCP may present no identifiable underlying pathology, may show increased heterogeneity and may be more challenging to treat. ${ }^{66} \mathrm{CNCP}$ may be classified further as neuropathic pain (peripheral and central), inflammatory pain (infectious, arthritic and postoperative pain), muscle pain (myofascial pain syndrome) and mechanical pain (LBP, neck-andshoulder pain). Various practice guidelines advocate the use of opioids as first-, second- or third-line therapy in CNCP, following failure of nonopioid analgesics. ${ }^{67,68}$ 


\section{Based on anatomic location}

For this purpose, anatomic location refers to a region or site where the actual pain may be localized, rather than the location of the body system where the pain originated. ${ }^{69}$ As per the IASP, pain is anatomically classified, regardless of origin, as localized to head, face and mouth pain; cervical pain; upper shoulder and upper limb pain; thoracic pain; abdominal pain; LBP, lumbar spine and coccyx pain; lower limb pain; pelvic pain; as well as anal, perineal and genital pain. ${ }^{70}$ Although this categorization helps in differential diagnosis, it cannot be used as a basis for therapeutic management. ${ }^{71}$

\section{Somatic pain}

Somatic pain is a sharp, well-localized pain emanating from the skin due to superficial damage and activation of peripheral nociceptors on the skin or mucous membranes. ${ }^{72}$ Alternatively, the pain may be deep and central in origin, originating from muscles, tendons or joints. Examples are LBP, neck pain, musculoskeletal pain and pain due to burns, injuries or wounds. ${ }^{73}$

\section{Visceral pain}

Visceral pain is deep, poorly localized pain resulting from pressure or damage to internal organs; it may be accompanied by low blood pressure, nausea or sweating as a response to stimulation of nerve endings that are at the site of pain and that relay signals to the CNS. Examples of visceral pain are gall/kidney stones, gastric ulcers or intestinal spasms. ${ }^{74,75}$

\section{Referred pain}

Pain that is felt at a site away from the site of injury is called referred pain. The origin of referred pain may be somatic (involving muscles or joints) or visceral (involving visceral organs).$^{76}$ Several mechanistic theories have been suggested to be involved in the cause of referred pain. Referred visceral pain may be attributed to the hyperexcitability of adjacent spinal neurons in response to nociceptive stimuli or a possible activation of the peripheral reflex arc via the efferent pathway. ${ }^{77}$ Examples of referred pain are myocardial pain and anginal pain.

\section{International Classification of Diseases, Eleventh Revision (ICD-I I) criteria for classification of chronic pain}

Although several methods of classification are available for the categorization of pain, there is a lack of accurate and consistent terminology for the coding of chronic pain in compliance with the ICD system used by the WHO. Responding to this, the IASP developed a system of classification of chronic pain based on the ICD criteria, which takes into consideration the etiology, location and pathophysiology of pain for better categorization of the disease. Categorization is based on multiple parenting, wherein each diagnosis falls under one primary category/parent but corresponds to more-than-one secondary categories. ${ }^{78}$ According to this classification, chronic pain may be categorized as primary pain, cancer pain, posttraumatic or postsurgical pain, neuropathic pain, headache and orofacial pain, and musculoskeletal and visceral pain.

\section{Pathophysiology of pain}

Regardless of its categorization, pain cannot be distinctly attributed to any isolated pathological event. Pain experience is a complex process that involves the activation of multiple neuronal signaling pathways within the peripheral nervous system (PNS) and central nervous system (CNS). ${ }^{73,79,80}$ The subjective experience of pain may be summarized as a fourstage process - transduction, transmission, modulation and perception. ${ }^{81}$ In stage 1 (transduction), nociceptive stimuli of tissue-damaging potential (including mechanical, chemical and thermal stimuli) are converted by the sensory cells into action potentials. Stage 2 (transmission) involves the conduction of these action potentials along afferent neurons to the $\mathrm{DH}$ of the spinal cord. In stage 3 (modulation), coding of nociceptive information occurs at the level of spinal DH. Modulation at the DH can be excitatory or inhibitory, thereby increasing or decreasing the resulting pain. Stage 4 involves generation of autonomic, affective, cognitive and behavioral responses to the painful stimulus, leading to pain perception.

\section{Sensitization \\ Peripheral sensitization}

Peripheral sensitization is characterized by abnormal sensitivity of afferent nociceptors to noxious stimuli. Nociceptors on the skin and deeper tissues sometimes become extremely sensitive to intense noxious stimuli in the presence of inflammation. This further lowers the threshold of nociceptor activation to normally innocuous or less-painful stimuli, accompanied by an increase in the degree or magnitude of response. Additionally, extreme sensitization may lead to the activation of sleeping or silent nociceptors, which upon excitation amplify the pain response manifold. Drugs acting at the peripheral nociceptor level are NSAIDs, opioids, cannabinoids and transient-receptor potential vanilloid (TRPV1) receptor antagonists. 


\section{Central sensitization}

Afferent pain signals from the peripheral nociceptors to the spinal neurons may sometimes activate low-threshold mechanoceptors at the $\mathrm{DH}$, thus amplifying the central neuronal response to noxious stimuli. ${ }^{82}$ This phenomenon of altered sensitivity of neuronal cells at the level of the second-order neuron is known as central sensitization. Central sensitization is implicated in the transition of acute pain to chronic degenerative pain. As observed with peripheral sensitization, primary hyperalgesia is the first manifestation of altered threshold at the central neuronal level. ${ }^{82}$ Under pathological conditions, receptors that are normally associated with sensory response to stimuli such as touch may acquire the ability to produce pain, resulting in secondary hyperalgesia, an important aspect of central sensitization. ${ }^{64}$ Unlike peripheral nociception, a number of neurochemical drivers are involved in the modulation of pain perception at the central level, resulting in a complex interplay of events that underlie the pathology of many chronic and neuropathic pain conditions (Figure 1)..$^{80,83}$

Drugs that modulate the pathways leading to central sensitization act by increasing the level of biogenic amines and reducing the spontaneous ectopic discharges. These include serotonin-norepinephrine reuptake inhibitors (SNRIs, such as duloxetine, paroxetine, venlafaxine), anticonvulsants (gabapentin and pregabalin) and tricyclic antidepressants (TCAs, such as amitriptyline, imipramine and desipramine). ${ }^{8486}$

\section{Wind-up phenomenon}

Wind-up is the temporal summation of excitatory impulses following repeated firing of spinal dorsal neurons due to C-fiber discharges.$^{64}$ The process of wind-up begins with the release of excitatory neurotransmitter glutamate, which binds to the $N$-methyl-D-aspartate receptor (NMDA) $/ \alpha$-amino-3hydroxy-5-methyl-4-isoxazolepropionic acid (AMPA) receptor. ${ }^{87}$ Activation of these receptors, together with release of substance $\mathrm{P}$ from the $\mathrm{C}$-fibers, initiates the depolarization of the cell membrane and triggers the intracellular release of $\mathrm{Ca}^{2+}$. Repetitive sensitization of NMDA receptors further contributes to hyperexcitability of the membrane, which aggravates the resulting response to pain, resembling an unending loop. ${ }^{80,88}$ Antagonism of NMDA receptor by drugs such as ketamine prevents the generation of excitatory response and provides therapeutic benefit in chronic neuropathic pain. ${ }^{89}$

\section{Neuroplasticity and pain}

Apart from central sensitization, inflammation induces significant changes in the neuroplastic structure of the brain and spinal cord. Altered neuroplasticity is a characteristic feature of neuropathic pain and is often a consequence of tissue damage or injury. ${ }^{90}$ The positive feedback-mediated structural repair following an injury or nerve damage may also contribute to selective degeneration and alteration of function, often progressing to the neuropathic state. ${ }^{91}$ Modulation of peripheral nociceptor function may result in painful neuropathies, characterized by heightened sensitivity to noxious or normal stimuli and a pricking, tingling or burning pain. On the contrary, central nerve damage triggered by infection, metabolic disorders or mechanical insult may result in loss of pain sensation such as in diabetic neuropathy. ${ }^{90}$

\section{Modulation of nociceptive traffic}

All events in the DH do not facilitate nociception. Spinal interneurons release amino acids (eg, $\gamma$-aminobutyric acid [GABA]) and neuropeptides (endogenous opioids) that bind to receptors on primary afferent and DH neurons and inhibit nociceptive transmission by presynaptic and postsynaptic mechanisms.

Descending transmission pathways are responsible for abolishing the ascending signals traveling up the central nervous system so that the pain perception is reduced, ${ }^{64}$ via release of endorphins and monoamines. ${ }^{92}$ Opioids like morphine act by modulation of both ascending and descending pain pathways (Figure 2).$^{93}$

\section{Progression from acute to chronic pain}

Acute and chronic pain cannot be segregated into two distinct types; chronic pain is rather an extension of acute pain, resulting from poorly managed acute pain. ${ }^{94}$ The metamorphosis of acute to chronic pain is believed to proceed through one of the following processes: central sensitization, modulation or modification of nociceptors, and altered neuroplasticity. ${ }^{95,96}$ Under normal circumstances, as a healing process begins, the noxious stimuli reduce and pain diminishes. However, in cases of persistent pain, peripheral and central sensitization most frequently transcends to hyperalgesia (increased response to less-painful stimuli) and allodynia (pain response to normally nonpainful stimuli). Altered spinal neuroplasticity as a result of glial cells modifying the neuronal cytoarchitecture is another important aspect of chronic pain and may be a consequence of repetitive nociceptive firing in the central neurons (reversible) or nerve damage due to neuropathy (irreversible). ${ }^{97}$ Studies have reported substantial loss of gray matter in the brain and changes in the structure, sensitivity and activity of neurons as well as internal rewiring in certain chronic pain conditions. ${ }^{91,98,99}$ These changes may be clinically manifested in the form of fibromyalgia or 
A Peripheral sensitization

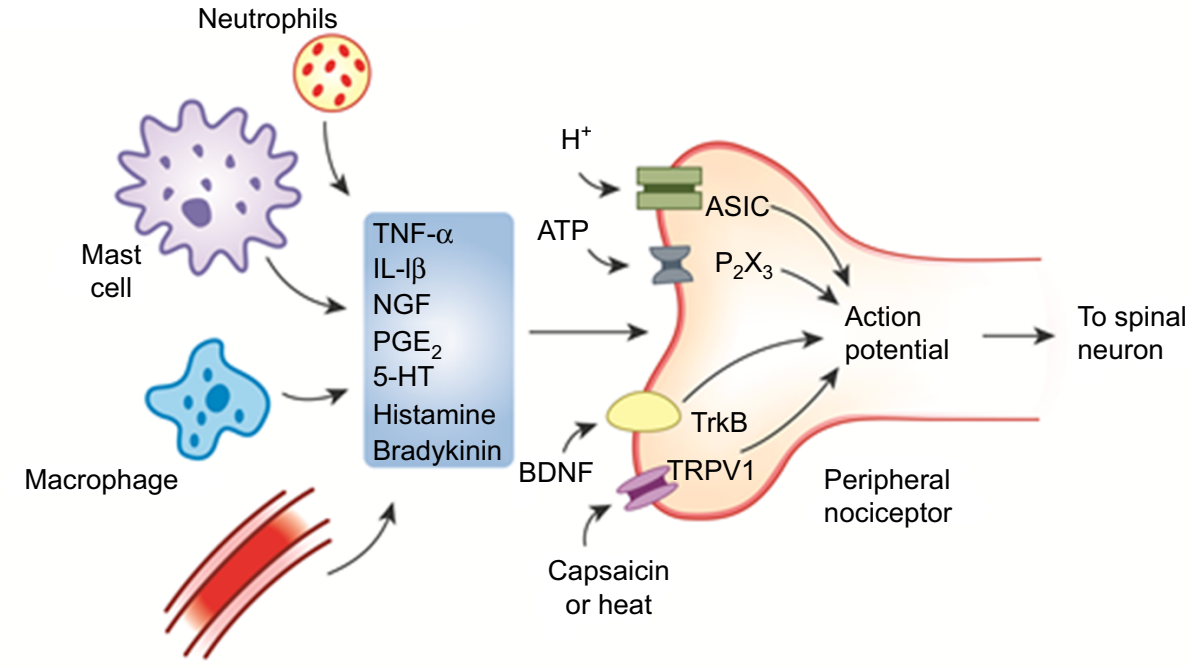

Blood vesse

B Central sensitization

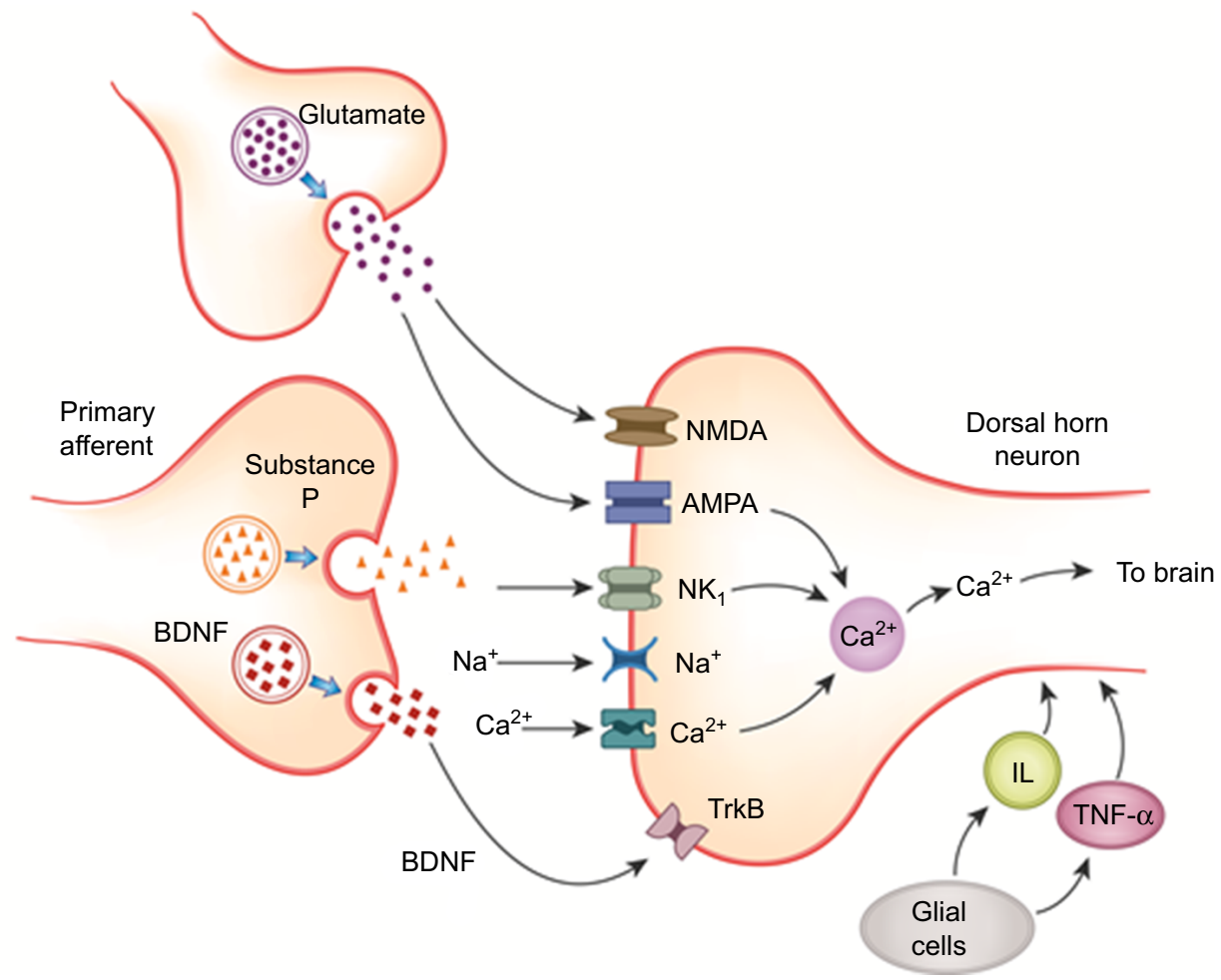

Figure I Mechanism of peripheral versus central sensitization.

Notes: (A) Peripheral sensitization and (B) central sensitization. Activation of peripheral nociceptors on the skin in response to stimuli, such as heat, injury or mechanical pressure, initiates the release of chemical mediators at the site of injury (peripheral sensitization). Persistent pain or inflammation causes activation and repetitive firing in afferent $\mathrm{C}$-fiber nociceptors, which triggers the release of excitatory neurotransmitter glutamate in the synapse of the dorsal horn (central sensitization). This is accompanied by the release of substance P, BDNF and neurokinins, which causes persistent depolarization of the cell membrane. Additionally, activation of AMPA or NMDA receptors by glutamate stimulates the microglia and subsequently induces the release of cyclooxygenase enzymes I and 2 , nitric oxide and other proinflammatory mediators (TNF- $\alpha$, IL-I, IL-6).

Abbreviations: AMPA, $\alpha$-amino-3-hydroxy-5-methyl-4-isoxazolepropionic acid receptor; ATP, adenosine triphosphate; ASIC, acid-sensing ion channels; BDNF, brainderived neurotropic factor; 5-HT, 5-hydroxytryptamine; IL, interleukin; NMDA, N-methyl-D-aspartate receptor; NGF, nerve growth factor; PG, prostaglandin; NK, neurokinin-I; TNF, tumor necrosis factor; TrkB, tyrosine receptor kinase B; TRPV, transient receptor potential vanilloid receptor.

complex regional pain syndrome. ${ }^{98}$ There is also a significant decline in neurotransmitter receptors and their function, which may explain the lack of efficacy with central opioid agonists in neuropathic pain. ${ }^{91}$ While management of acute pain symptoms might seem to be the most rational approach from a clinician's perspective, it is essential to evaluate the 


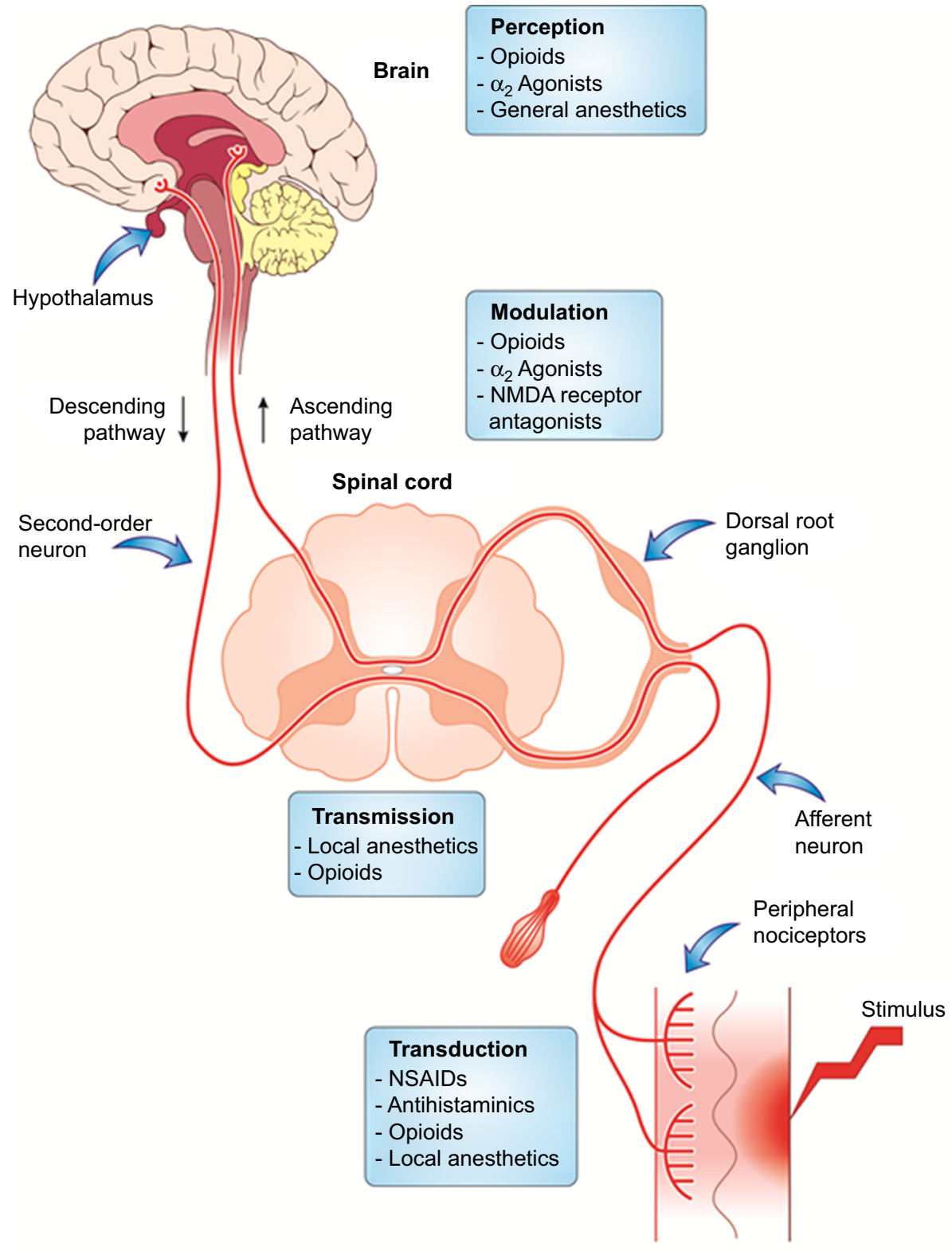

Skin

Figure 2 Therapeutic modulation of the pain-processing pathway.

Abbreviations: NMDA, N-methyl-D-aspartate receptor; NSAID, nonsteroidal anti-inflammatory drug.

risk factors associated with pain chronification. ${ }^{100}$ Increased pain intensity, loss of functionality and affected psychosocial ability are a few predictive factors for development of chronic pain. ${ }^{101,102}$ Studies have shown that assessment of functional and psychosocial outcomes is a highly favorable measure in predicting the risk of chronic pain. ${ }^{103,104}$

\section{Undertreatment of pain}

Pain is the most prevalent, yet frequently undertreated, medical condition globally. ${ }^{105,106}$ Untreated or inadequately treated pain is the major cause of depression and eventually leads to loss of productivity and functionality, as well as poor health-related QoL, of patients. ${ }^{107,108}$ There are several impediments that contribute to the undertreatment of pain in India, which include lack of awareness, regulatory restrictions on opioid use, physician attitudes, overuse of NSAIDs and insufficient resources for managing pain in primary care settings. ${ }^{42,109-111}$ It is essential to minimize these barriers to ensure optimal treatment of pain.

\section{Therapeutic management of pain Evolution of analgesics}

In the wake of increased understanding of the pathophysiology of pain, various receptors have been identified as potential 
targets for drug therapy over the years. In the early 1970s, Vane et $\mathrm{al}^{112}$ proposed the involvement of prostaglandin inhibition as the mechanism of action of aspirin-like drugs. These findings paved the path for development of NSAIDs, targeting the COX-1 enzyme system involved in the synthesis of prostaglandins, thereby reducing both pain and associated inflammation. The earliest known marketed NSAIDs were ibuprofen and aspirin, which were followed up by similar compounds, with varying efficacies. ${ }^{113}$ Acetaminophen, the safest analgesic till date was developed in 1946, after two synthetic antipyretics, acetanilide and phenacetin, were developed and had significant associated toxicities. ${ }^{114}$ In the search for a more effective and safer analgesic, research was focused on the development of the selective COX-2 inhibitors celecoxib and rofecoxib. ${ }^{115}$ However, there were severe concerns of cardiac toxicities observed with these agents, limiting their use.

Morphine and codeine were the earliest natural opioid analgesics to be developed and used in clinical practice. Further research led to the development of synthetic opioids such as fentanyl and pethidine, with increased efficacy and long-term activity. However, in the light of associated risk of overuse, addiction and misuse of these analgesics, it was recommended to follow a risk-management and monitoring program during opioid therapy. Tramadol, an opioid analgesic different from conventional opioids, was developed in 1977 and has since been routinely used in moderate-to-severe pain, owing to its high safety and efficacy.

Further scientific investigation into pain pathology has led to the development of anti-nerve growth factor (antiNGF)- and anti-TRPV1-based therapies. However, these agents are still under clinical development, and there is a lack of conclusive evidence supporting their efficacy and safety in routine clinical practice. ${ }^{116,117}$ Deeper insights into the central pain pathways have uncovered some overlapping pathological factors implicated in pain, depression and other psychological disorders. ${ }^{118}$ Antidepressant-induced increase in the neurotransmitters serotonin and norepinephrine has been thought to alleviate pain, the postulation being reinforced by the remarkable efficacy shown by antidepressants in chronic pain, particularly of neuropathic origin. ${ }^{119}$ Similarly, the efficacy of the anticonvulsants pregabalin, gabapentin and carbamazepine was demonstrated in several clinical studies. ${ }^{120}$ As a guidance to physicians treating chronic cancer pain, the WHO established an evidence-based threestep analgesic ladder that provides a stepwise approach for deciding treatment according to the intensity of pain. ${ }^{121}$ This ladder has been widely adopted for use in noncancer pain settings. ${ }^{122}$ However, the three-step ladder is not considered applicable anymore and has been modified to suit different clinical settings, due to the practical delays in administering pain relief for patients with severe pain and also due to concerns over the efficacy of low-dose opioids used in step two.

Evidence from several studies has highlighted the importance of nonpharmacological interventions for pain relief. ${ }^{123}$ Exercises such as stretching and strengthening, relaxation, postural stabilization and yoga; therapeutic heat and cold packs; ergonomic adaptations; modification of daily activities; chiropractic treatment; massage or traction are some of the nonpharmacological approaches that are routinely used with pharmacological therapy. ${ }^{124-129}$

\section{Therapeutic drug classes}

A list of available therapies for pain management is represented in Table 2.

\section{Need for individualized pain management}

An individual's perception of pain may be greatly influenced by the emotional and behavioral responses and is strongly correlated to his/her culture, personal history and genetic makeup. ${ }^{130-133}$ For instance, presence of different haplotypes of the catecholamine-O-methyltransferase gene has been linked to variability in pain perception in humans. ${ }^{134}$ Thus, treatment for pain must be tailored for each individual and should focus on interruption of reinforcement of the pain behavior and modulation of the pain response. Important factors for consideration for treatment recommendation include individual's response to prior appropriate treatment management, compliance and drug abuse/dependence behavior. ${ }^{56}$ The biopsychosocial model of pain encompasses the biological, psychological and social aspects of pain and has been increasingly used in a variety of chronic pain settings. ${ }^{135,136}$ Since the experience of pain is heterogenic in nature; a "one size fits all" approach would not be the most ideal way to manage pain. In short, an individualized approach to treatment based on the genetic, cultural, social and behavioral aspects of the patient may help in the optimal management of pain across different clinical settings. ${ }^{56,137}$

\section{Role of combination therapies}

Combination therapies may consist of combination of two or more drugs administered separately or as fixed-dose combinations (FDCs) of two or more active ingredients in a single-dosage form. ${ }^{138}$ Use of FDCs of analgesics represents a multimodal approach that is based on the integration of 
Table 2 Available therapies for treatment of pain

\begin{tabular}{|c|c|c|c|c|}
\hline Class & Molecules & Indications & Dosage & Common adverse events \\
\hline Aniline analgesics & Acetaminophen & $\begin{array}{l}\text { Acute/chronic } \\
\text { pain }\end{array}$ & $\begin{array}{l}500-1,000 \mathrm{mg} \text { every } 4-6 \mathrm{~h} ; \\
\max \text { dose of } 4,000 \mathrm{mg} / \mathrm{d}\end{array}$ & Hepatotoxicity \\
\hline NSAIDs-Salicylate & Aspirin & $\begin{array}{l}\text { Acute/chronic } \\
\text { pain }\end{array}$ & $\begin{array}{l}500-1,000 \mathrm{mg} \text { every } 4-6 \mathrm{~h} \text {; } \\
\max \text { dose of } 4,000 \mathrm{mg} / \mathrm{d}\end{array}$ & $\begin{array}{l}\text { Gl upset/irritation, hepatic and renal dysfunction, fluid } \\
\text { retention, hypersensitivity reaction }\end{array}$ \\
\hline $\begin{array}{l}\text { NSAIDs-Aryl } \\
\text { acetic acid } \\
\text { derivative }\end{array}$ & Diclofenac & $\begin{array}{l}\text { Acute/chronic } \\
\text { pain }\end{array}$ & $50-100 \mathrm{mg} / \mathrm{d} ; \max 150 \mathrm{mg} / \mathrm{d}$ & $\begin{array}{l}\text { Gl upset/irritation, nausea and vomiting, weakness, } \\
\text { headache, dizziness, hepatic and renal dysfunction, } \\
\text { hypersensitivity reaction }\end{array}$ \\
\hline \multirow[t]{2}{*}{$\begin{array}{l}\text { NSAIDs- } \\
\text { Propionate }\end{array}$} & Ibuprofen & Acute pain & $\begin{array}{l}400-800 \mathrm{mg} \text { every } 6-8 \mathrm{~h} \text {; } \\
\mathrm{max} \text { dose of } 3,200 \mathrm{mg} / \mathrm{d}\end{array}$ & $\begin{array}{l}\text { Gl upset/irritation, hepatic and renal dysfunction, fluid } \\
\text { retention, hypersensitivity reaction, cardiovascular events } \\
\text { in high-risk patients }\end{array}$ \\
\hline & Naproxen & Chronic pain & $\begin{array}{l}250-500 \mathrm{mg} \text { every } 8-12 \mathrm{~h} \text {; } \\
\text { max dose of } \mathrm{I}, 500 \mathrm{mg} / \mathrm{d}\end{array}$ & $\begin{array}{l}\text { Gl upset/irritation, hepatic and renal dysfunction, fluid } \\
\text { retention, hypersensitivity reaction, cardiovascular events } \\
\text { in high-risk patients }\end{array}$ \\
\hline \multirow[t]{2}{*}{ COX-2 inhibitor } & Colecoxib & $\begin{array}{l}\text { Acute/chronic } \\
\text { pain }\end{array}$ & $\begin{array}{l}200-400 \mathrm{mg} \text { every I2-24 h; } \\
\mathrm{max} \text { dose of } 400 \mathrm{mg} / \mathrm{d}\end{array}$ & $\begin{array}{l}\text { Gl upset/irritation, hepatic and renal dysfunction, fluid } \\
\text { retention, hypersensitivity reaction, cardiovascular events } \\
\text { in high-risk patients }\end{array}$ \\
\hline & Rofecoxib & $\begin{array}{l}\text { Acute/chronic } \\
\text { Pain }\end{array}$ & $12.5-50 \mathrm{mg}$ once a day & $\begin{array}{l}\text { Gl upset/irritation, hepatic and renal dysfunction, fluid } \\
\text { retention, hypersensitivity reaction, cardiovascular events } \\
\text { in high-risk patients }\end{array}$ \\
\hline \multirow[t]{5}{*}{ Opiate } & Codeine & Chronic pain & $\begin{array}{l}30-60 \mathrm{mg} \text { every } 4 \mathrm{~h} \text { as } \\
\text { needed }\end{array}$ & $\begin{array}{l}\text { Constipation, nausea, vomiting, sedation and pruritus; } \\
\text { less common effects include dry mouth, mental } \\
\text { confusion, urinary retention and respiratory depression }\end{array}$ \\
\hline & Hydrocodone & Chronic pain & $\begin{array}{l}5-10 \mathrm{mg} \text { every } 4 \mathrm{~h} \text { as } \\
\text { needed }\end{array}$ & $\begin{array}{l}\text { Constipation, nausea, vomiting, sedation and pruritus; } \\
\text { less common effects include dry mouth, mental } \\
\text { confusion, urinary retention and respiratory depression }\end{array}$ \\
\hline & Oxycodone & Chronic pain & $\begin{array}{l}5-10 \mathrm{mg} \text { every } 4 \mathrm{~h} \text { as } \\
\text { needed }\end{array}$ & $\begin{array}{l}\text { Constipation, nausea, vomiting, sedation and pruritus; } \\
\text { less common effects include dry mouth, mental } \\
\text { confusion, urinary retention and respiratory depression }\end{array}$ \\
\hline & Morphine & Chronic pain & $5-30 \mathrm{mg}$ every $4 \mathrm{~h}$ & $\begin{array}{l}\text { Constipation, nausea, vomiting, sedation and pruritus; } \\
\text { less common effects include dry mouth, mental } \\
\text { confusion, urinary retention and respiratory depression }\end{array}$ \\
\hline & Tramadol & $\begin{array}{l}\text { Acute/chronic } \\
\text { pain }\end{array}$ & $\begin{array}{l}5-100 \mathrm{mg} \text { every } 4-6 \mathrm{~h} \text {; } \\
\mathrm{max} \text { dose of } 400 \mathrm{mg} / \mathrm{d}\end{array}$ & $\begin{array}{l}\text { Constipation, somnolence, dizziness, nausea, vomiting } \\
\text { and pruritus }\end{array}$ \\
\hline \multirow[t]{4}{*}{ Antiepileptic } & Gabapentin & $\begin{array}{l}\text { Acute/chronic } \\
\text { pain }\end{array}$ & $\begin{array}{l}300-900 \mathrm{mg} \text { thrice daily; } \\
\max \text { dose of } 3,600 \mathrm{mg} / \mathrm{d}\end{array}$ & Dizziness, somnolence and peripheral edema \\
\hline & Pregabalin & $\begin{array}{l}\text { Acute/chronic } \\
\text { pain }\end{array}$ & $50-300 \mathrm{mg} / \mathrm{d}$ & Dizziness, somnolence and peripheral edema \\
\hline & Carbamazepine & $\begin{array}{l}\text { Acute/chronic } \\
\text { pain }\end{array}$ & 200-600 mg twice daily & Somnolence, mental confusion, dizziness and nausea \\
\hline & Oxcarbazepine & $\begin{array}{l}\text { Acute/chronic } \\
\text { pain }\end{array}$ & $1,200-2,400 \mathrm{mg} / \mathrm{d}$ & Changes in vision, dizziness, confusion and depression \\
\hline $\begin{array}{l}\text { Tricyclic } \\
\text { antidepressants }\end{array}$ & $\begin{array}{l}\text { Amitriptyline, } \\
\text { nortriptyline }\end{array}$ & Acute pain & $\begin{array}{l}10-150 \mathrm{mg} / \mathrm{d} \text { (amitriptyline), } \\
25-100 \mathrm{mg} / \mathrm{d} \text { (nortriptyline) }\end{array}$ & Drowsiness, dry mouth, dizziness and constipation \\
\hline SNRIs & $\begin{array}{l}\text { Duloxetine, } \\
\text { venlafaxine }\end{array}$ & Chronic pain & $\begin{array}{l}40-60 \mathrm{mg} / \mathrm{d} \text { (duloxetine), } \\
150 \mathrm{mg} / \mathrm{d} \text { (venlafaxine) }\end{array}$ & $\begin{array}{l}\text { Nausea, gastrointestinal bleeding and increase in hepatic } \\
\text { enzymes }\end{array}$ \\
\hline
\end{tabular}

Notes: Data from American Geriatrics Society Panel on the Pharmacological Management of Persistent Pain in Older Persons (2009), ${ }^{29}$ Patel et al, ${ }^{38}$ McPherson et al (2004), ${ }^{239}$ Bell and Schnitzer (200I), ${ }^{240}$ Antman et al (2007), ${ }^{241}$ Dworkin et al (2010), ${ }^{242}$ and Cleeland and Ryan. ${ }^{243,244}$

Abbreviations: d, day; h, hour; max, maximum; COX, cyclooxygenase; GI, gastrointestinal; NSAIDs, nonsteroidal anti-inflammatory drugs; SNRI, serotonin-norepinephrine reuptake inhibitor.

various mechanisms to result in pain relief. ${ }^{139}$ FDCs have been hugely preferred to treat a variety of disorders owing to their safety and efficacy. Additionally, use of FDCs may improve patient adherence to therapy and reduce the cost associated with multiple medications. ${ }^{140}$ However, not all FDCs are rational, and the majority of them may present no evidence of improved efficacy or tolerability. ${ }^{141,142}$ In India, FDCs have been used generously, notwithstanding the complete lack of efficacy with some combinations. ${ }^{143}$ The Central Drugs Standard Control Organization (CDSCO) has taken cognizance of 
the increased use of irrational drug combinations by physicians in India and has recently banned more than 300 FDCs from the market. ${ }^{144}$ From a physician's perspective, the rationale for use of FDCs must identify clear association between FDC use and increased efficacy or reduced adverse events. Furthermore, from a regulatory perspective, the components of an FDC must possess complementary pharmacokinetic profiles and should not have supra-additive toxicity.

The US Food and Drug Administration (USFDA) draft guidance for industry mandates the fulfillment of some necessary conditions prior to the approval of analgesic FDCs. Thus, an FDC awaiting FDA approval must demonstrate strong evidence of efficacy over the available single-agent therapy in well-controlled single- or multiple-dose clinical studies. Moreover, each component of the FDC must contribute to the overall efficacy and safety of the product, in order to justify its use over single-agent therapies. ${ }^{145}$ A similar guidance document has been developed by the CDSCO to guide the development of FDCs in India. ${ }^{146} \mathrm{~A}$ list of approved analgesic FDCs in India is provided by the CDSCO. ${ }^{147}$

\section{Reasons for mismanagement of pain}

Adequate treatment according to national and international treatment guidelines can result in sufficient pain relief in majority of the patients. However, barriers to the use of analgesics can result in undertreatment of pain. Other than institutional barriers such as government regulations regarding opioid prescription and irregularities in the treatment of patients with pain, physician and patient barriers hinder effective management of pain.

\section{Physician barriers}

Physician's knowledge and understanding regarding patients' pain, principles of treating pain, analgesics ladder and knowledge about the efficacy of different routes of opioid administration are very important for pain management. ${ }^{148-152}$ Another factor affecting inadequate assessment of pain by physicians included concerns regarding side effects or tolerance to opioids. ${ }^{43,153-155}$ In cancer patients, inadequate pain assessment was considered a major barrier (20\%-80\%) in pain assessment. ${ }^{42,148,149}$ The physicians either do not use an appropriate method to measure the pain intensity or fail to appropriately classify the pain. Misconceptions regarding the regulations governing opioid use also exist. ${ }^{156}$

Concerns regarding addiction to or physical dependence on, as well as side effects of opioids prevent physicians from prescribing opioids according to standardized guidelines. ${ }^{68,127,157-159}$ According to the guidelines by the
WHO, strong opioids should be the first choice of treatment for moderate-to-severe pain and the use of these opioids must be continuously personalized based on patients' response in terms of pain relief. In a study by Tournebize et al, ${ }^{160}$ more than $50 \%$ of surveyed physicians reported insufficient adherence to treatment guidelines for chronic pain. Studies have also shown that physicians hesitate to administer adequate doses of opioids because of the fear of the potential development of tolerance by the patient. ${ }^{42,161,162}$ Most often, physicians do not consider assessment of pain as a priority and, as a result, do not give pain relief its due importance. Furthermore, a patient's self-report of pain, considered the best indication of pain, is viewed with skepticism.

\section{Patient barriers}

Cognitive barrier results from patients' lack of understanding about the different options of pain management, along with attitudes and beliefs that not only affect patients' pain communication and adherence to analgesic regimen but also have a negative impact on the outcomes of pain management. ${ }^{163}$

Many patients lack the knowledge of the principles involved in effective pain management and have concerns about taking pain medication (mostly concerns about addiction and side effects of pain medication). A few researchers believe that there is a relationship between better knowledge and less pain intensity or between more negative beliefs and more intensive pain. ${ }^{164-169}$ However, this association was either partially confirmed or not confirmed by other researchers. ${ }^{170,171}$

Patients beliefs and attitudes that hinder pain management include the following: fear of addiction, that originates from a misunderstanding of the relationship between psychological addiction, physical dependence and tolerance; concerns about analgesic use (side effects); concerns about pain communication due to age, language, cultural traditions or other illness (communication issues between patients, nurses and doctors [sensory barrier]; willingness to tolerate pain to be a good patient and to not trouble the family); not adapting adequately to the possibility of controlling pain in general (stigma of using pain medication, stoicism about dealing with pain, assuming that pain is a part of the disease and suffering, concerns regarding the capability of the caregiver to understand their needs, hesitation to question authority); and inadequate adherence to pain medication (sensory barrier). ${ }^{42,155,166,169,172-175}$ Financial barriers could also result in reduced adherence to treatment. 


\section{Management myths}

Several myths about pain and its treatment exist in our society, which ultimately prevent the patient from receiving adequate care. According to the American Chronic Pain Association, some of the commonly accepted beliefs revolve around the perception (pain is an emotional and not a physical disorder) and treatment of pain (analgesic therapies may not be effective or may lead to addiction). ${ }^{176}$ In addition, undertreatment of pain in the elderly and children may be primarily due to the assumption that pain cannot be felt by newborns and babies but is an acceptable and natural part of the aging process and therefore may not warrant medical attention. ${ }^{177}$ It is essential to disprove these myths by promoting awareness among patients, physicians and the society in general.

\section{Comorbidities}

Presence of comorbid medical conditions may not only influence the response to analgesics but may present difficulties in diagnosis as well. The most commonly associated psychological comorbidities in pain are depression and anxiety. ${ }^{178-180}$ These may be preexisting or may result from the pain itself, often aggravated in untreated or undertreated chronic pain. ${ }^{181}$ Presence of depression is known to have considerable impact on outcomes of pain treatment, signifying the two-way relationship between pain and depression. A systematic review of studies correlating the effect of depression on pain showed increased severity, intensity and duration of pain in depressed patients. ${ }^{124}$ Functional assessment using valid tools may indicate the presence of underlying symptoms, necessitating the use of antidepressant therapy, which can in turn effectively help control pain. ${ }^{126,182}$ Until recently, the outcome of pain therapies was evaluated on the basis of reduction in pain intensity and improvement in sensory/motor ability, seldom delving into the psychological or cognitive aspects that frequently led to mismanaged pain. Clinical investigations over the years have resulted in the use of cognitive behavioral therapy in pain treatment programs, with remarkable efficacy in the acute and chronic pain settings. ${ }^{183,184}$

\section{Management recommendations General considerations (evaluating a patient with pain)}

The recommendations are based on graded evidence as explained previously. The grades are mentioned in parenthesis next to each recommendation.

\section{History}

- A thorough evaluation of the patient profile, patient history and presence of comorbid conditions is necessary as a first step toward pain diagnosis (C).

- Diagnosis should involve measurement of pain intensity, physical examination, sensory examination, motor examination and evaluation of cognitive and functional well-being (B).

\section{Assessment and monitoring}

- Identify and use appropriate pain assessment tools (A) For the purpose of designing treatment strategies for managing pain, it is essential to assess the severity of the pain. Use of pain assessment scales may help in the diagnosis of the disease, design of treatment strategies, monitoring and evaluation of outcome of therapy or for predicting the impact of pain on functional outcomes of a patient (Table 3). ${ }^{185}$ Factors that should be taken into consideration while selecting the appropriate pain assessment method include sensitivity and specificity, usefulness or value of the assessment tool, objective of the assessment, age of the patient and extent of symptoms presented by the patient. ${ }^{186}$

- Sensory examination

Components of a sensory examination include light touch, pinprick, temperature (hot or cold) and vibration. ${ }^{187}$ Quantitative sensory testing (QST) might help distinguish between various types of neuropathic pain. ${ }^{188,189}$ In patients with neuropathy, the threshold for pinprick and thermal sensations are increased, while increased sensitivity to light touch may indicate presence of allodynia or hyperalgesia, which may point toward painful inflammation or fibromyalgia with a central neuropathic origin. ${ }^{190-192}$ The QST has also been used in the diagnosis of osteoarthritis and other musculoskeletal conditions, although not as a sole measure. ${ }^{193}$

- Motor examination

Evaluation of motor function is an important method of diagnosing musculoskeletal pain, especially back pain and neck pain. Exercises such as neck rotation and neck flexion or extension tests may help determine the localization and intensity of pain (D). ${ }^{194}$

- Diagnostic tests

Examination by X-rays is the most common method used to confirm the localization of pain, particularly in 
Table 3 Different pain assessment scales for measuring the intensity of pain

\begin{tabular}{|c|c|c|c|c|c|}
\hline $\begin{array}{l}\text { Assessment } \\
\text { scale }\end{array}$ & $\begin{array}{l}\text { Number } \\
\text { of items }\end{array}$ & Components & Outcome & Applicability & Limitation \\
\hline \multicolumn{6}{|c|}{ Unidimensional pain scales } \\
\hline VAS & $1-10$ & $\begin{array}{l}\text { Numerical scale } \\
\text { (0: no pain; to } 10 \text { : unbearable pain) }\end{array}$ & Pain intensity & $\begin{array}{l}\text { Adults with acute or } \\
\text { chronic pain }\end{array}$ & $\begin{array}{l}\text { Cognitively affected adults, } \\
\text { elderly and children }\end{array}$ \\
\hline VRS & $1-10$ & $\begin{array}{l}\text { Verbal descriptor scale } \\
\text { (0: no pain; to 10: worst imaginable pain) }\end{array}$ & Pain intensity & $\begin{array}{l}\text { Adults with acute or } \\
\text { chronic pain }\end{array}$ & $\begin{array}{l}\text { Illiterate and cognitively } \\
\text { affected }\end{array}$ \\
\hline NRS & $1-10$ & $\begin{array}{l}\text { Numerical scale with markings } \\
\text { (0: no pain; to I0: worst imaginable pain) }\end{array}$ & Pain intensity & $\begin{array}{l}\text { Adults with chronic } \\
\text { pain, elderly and } \\
\text { illiterate population }\end{array}$ & - \\
\hline $\begin{array}{l}\text { Faces Pain } \\
\text { Scale }\end{array}$ & $1-10$ & $\begin{array}{l}\text { Pictoral representation of faces } \\
\text { expressing varying degrees of pain } \\
\text { (0: no pain; to 10: worst pain) }\end{array}$ & Pain intensity & $\begin{array}{l}\text { Children, elderly or } \\
\text { cognitively impaired } \\
\text { patients }\end{array}$ & $\begin{array}{l}\text { Subjective differences in } \\
\text { interpretation of scale } \\
\text { may affect results }\end{array}$ \\
\hline \multicolumn{6}{|c|}{ Multidimensional pain scales } \\
\hline BPI & 4-item scale & $\begin{array}{l}4 \text { grades for pain severity (0: no pain; to } \\
\text { 10: pain as bad as you can imagine) } \\
\text { and } 7 \text { grades for pain interference on a } \\
7 \text {-item scale (0: does not interfere; to } 10 \text { : } \\
\text { completely interferes) }\end{array}$ & $\begin{array}{l}\text { Pain intensity and } \\
\text { functional status }\end{array}$ & $\begin{array}{l}\text { Adults with chronic } \\
\text { pain due to cancer, } \\
\text { rheumatoid arthritis or } \\
\text { peripheral neuropathy }\end{array}$ & - \\
\hline MPQ & 78 words & $\begin{array}{l}4 \text { classes of descriptors with } 78 \text { items } \\
\text { ( } 20 \text { groups of words) to describe the } \\
\text { quality of pain }\end{array}$ & $\begin{array}{l}\text { Subjective pain } \\
\text { experience }\end{array}$ & $\begin{array}{l}\text { Adults with neuropathic, } \\
\text { arthritic and other types } \\
\text { of chronic pain }\end{array}$ & $\begin{array}{l}\text { Time consuming, } \\
\text { difficult to administer to } \\
\text { cognitively affected or } \\
\text { illiterate patients }\end{array}$ \\
\hline \multicolumn{6}{|c|}{ Disease-specific pain scales } \\
\hline $\begin{array}{l}\text { Neuropathic } \\
\text { pain scale }\end{array}$ & 10 items & $\begin{array}{l}\text { Verbal descriptors of pain } \\
\text { (0: no pain; to I0: most sharp/dull/hot/ } \\
\text { intense/cold sensation imaginable) }\end{array}$ & $\begin{array}{l}\text { Intensity, quality } \\
\text { and mechanism } \\
\text { of pain }\end{array}$ & $\begin{array}{l}\text { Postherpetic neuralgia, } \\
\text { diabetic neuropathy }\end{array}$ & \\
\hline $\begin{array}{l}\text { LANSS Pain } \\
\text { Scale }\end{array}$ & 7 items & $\begin{array}{l}\text { Interview and sensory examination } \\
\text { (allodynia, altered pinprick threshold) }\end{array}$ & $\begin{array}{l}\text { Intensity and } \\
\text { mechanism of pain }\end{array}$ & $\begin{array}{l}\text { Differentiation between } \\
\text { neuropathic and } \\
\text { nonneuropathic pain }\end{array}$ & \\
\hline RAPS & 24 items & $\begin{array}{l}\text { Pain severity and interference } \\
\text { (0: never; to 6: always) }\end{array}$ & $\begin{array}{l}\text { Pain intensity and } \\
\text { functional status }\end{array}$ & Rheumatoid arthritis & \\
\hline \multicolumn{6}{|c|}{ Pain scales for elderly patients } \\
\hline $\begin{array}{l}\text { Abbey's Pain } \\
\text { Scale }\end{array}$ & 6 items & $\begin{array}{l}\text { Nonverbal descriptors of pain severity } \\
\text { (0: absent, I: mild, 2: moderate, } 3 \text { : severe) }\end{array}$ & $\begin{array}{l}\text { Pain intensity, } \\
\text { physical and } \\
\text { behavioral changes }\end{array}$ & $\begin{array}{l}\text { Elderly patients with } \\
\text { dementia }\end{array}$ & $\begin{array}{l}\text { Self-reporting of pain not } \\
\text { possible }\end{array}$ \\
\hline PADE & 24 items & Behavioral descriptors & $\begin{array}{l}\text { Physical, global } \\
\text { (pain intensity) and } \\
\text { functional status }\end{array}$ & $\begin{array}{l}\text { Elderly patients with } \\
\text { dementia }\end{array}$ & $\begin{array}{l}\text { Inconsistent narrative } \\
\text { descriptors, difficult to } \\
\text { administer by caregivers }\end{array}$ \\
\hline
\end{tabular}

Abbreviations: BPI, Brief Pain Inventory; LANSS, Leeds Assessment of Neuropathic Symptoms and Signs; MPQ, McGill Pain Questionnaire; NRS, Numerical Rating Scale; PADE, Pain Assessment for the Dementing Elderly; RAPS, Rheumatoid Arthritis Pain Scale; VRS, Verbal Rating Scale; VAS, Visual Analog Scale.

LBP, neck pain, joint pain or pain associated with internal organs. ${ }^{147}$ Use of computed tomography (CT) scan or magnetic resonance imaging (MRI) might be useful in cases in which diagnosis by physical examination or $\mathrm{X}$-ray may be insufficient or if any underlying damage to the CNS is suspected to be involved. ${ }^{195}$ Further details are presented in the Supplementary material section.

\section{Comorbidities}

Since comorbidities may influence pain perception and affect the treatment outcomes, it is necessary to carry out screening of the patient for possible physical illnesses (liver impairments, gastrointestinal diseases, renal impairments, physical dependence to opioids and so on) and psychiatric comorbidities (depression, anxiety, psychological disorders) prior to initiating treatment (Figure 3).

\section{Decide treatment goals}

Prior to starting treatment, it is essential to decide the treatment goals so as to prevent undertreatment. It is important to consider the ethical implications of the associated treatment. The following questions may help: how severe is the pain? Is the pain associated with disability or loss of function? What are the existing comorbidities? Is psychosocial function impaired? Is opioid therapy required?

According to Cohen and Jangro, ${ }^{196}$ treatment goals need to be broader, achieving a little more than pain reduction (must include QoL and the functional impact of pain treatment), 


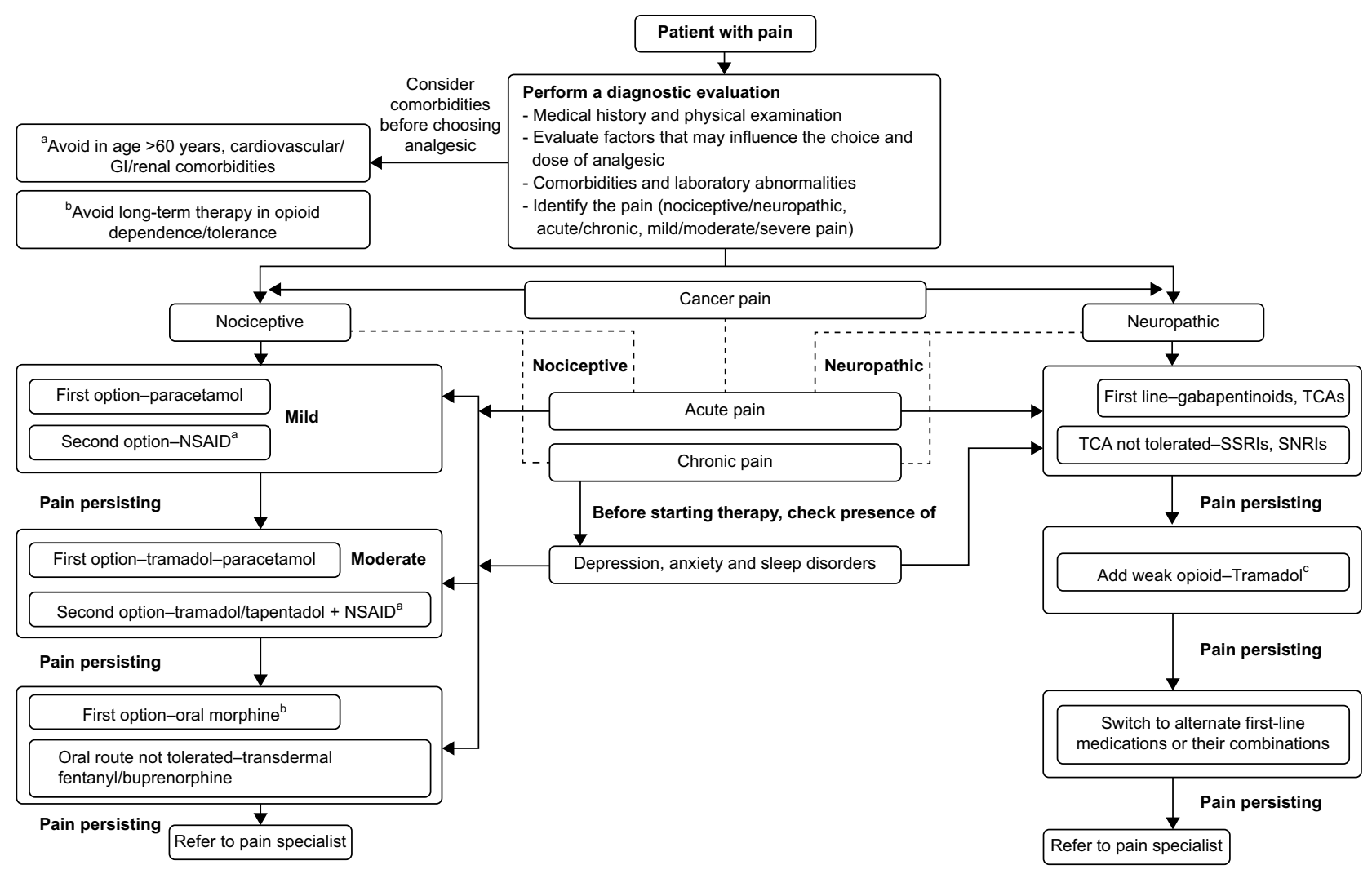

Figure 3 Pain algorithm.

Notes: ${ }^{a}$ Avoid in age $>60$ years, cardiovascular/GI/renal comorbidities; 'bavoid long-term therapy in opioid dependence/tolerance; 'first-line therapy for acute NP, NP due to cancer, acute exacerbations of severe NP as well as when titrating one of the first-line medications, if prompt relief of pain is required.

Abbreviations: GI, gastrointestinal; NP, neuropathic pain; NSAID, nonsteroidal anti-inflammatory drug; SNRI, serotonin-norepinephrine reuptake inhibitor; SSRI, selective serotonin reuptake inhibitor; TCA, tricyclic antidepressant.

and must be realistic, in order to ensure optimal therapy with minimal side effects.

\section{Investigations for neuropathic pain}

A detailed diagnosis of neuropathic pain involves, in addition to pain assessment tools (using neuropathic pain scales) and QST, evaluation of neurological function using functional neuroimaging, neurophysiology studies, skin biopsy techniques and other laboratory testing methods. ${ }^{197}$ Additional laboratory investigations include microneurography studies, laser-evoked potentials, electrophysiology studies and nociceptive reflexes. ${ }^{189}$

\section{Pharmacological management}

In order to understand the nature of pain and to determine the treatment course, it is essential to distinguish the physical causes of pain in addition to assessing the mental and environmental factors.

The choice of analgesic prescribed is based on the type of pain, duration of pain and comorbidities. A few years ago, NSAIDs, acetaminophen and opioids were prescribed in the treatment of all types of pain. This methodology is now considered ineffective, and with an increase in the awareness regarding different classifications of pain, mechanismspecific treatment is recommended.

\section{Comorbidities influencing analgesic use}

Studies have shown that a number of comorbidities influence the treatment outcomes of analgesic therapy. It is widely known that several chronic pain conditions are accompanied by psychosocial comorbidities such as anxiety and depression, which may amplify the pain perception, physical function, adaptation and treatment response. ${ }^{198,199}$ Systematic screening of patients for any associated psychiatric comorbidity may support the physician in deciding the treatment plan. In the case of suspected depression, antidepressants may be added to the therapeutic regimen to control the clinical symptoms. ${ }^{200}$ While psychiatric comorbidities significantly affect the emotional response to pain, any coexisting physical comorbidities may affect the efficacy and tolerability of the analgesic. For example, decreased liver function may significantly affect the metabolism of NSAIDs and opioids, leading to increased levels in blood and associated toxicity. Preliminary screening by performing liver function tests and assessment of the Child-Pugh score may be important in determining liver failure. ${ }^{201}$ Similar 
considerations are necessitated in suspected gastrointestinal or renal comorbidities. ${ }^{202,203}$

\section{Duration of pain}

Duration of pain is a decisive factor guiding the choice of an appropriate analgesic regimen. ${ }^{204}$ However, duration of pain should always be correlated with the pain intensity. ${ }^{158,199}$

\section{- Acute pain}

The primary pain management goal here is early intervention to reduce the pain to acceptable levels. Most of the acute pain is nociceptive and treatment for acute pain involves a combination of paracetamol, opioids and some topical agents. Mild somatic acute pain could be treated with paracetamol, NSAIDs, topical anesthetics and physical treatments such as ice, compression and so on. For acute visceral pain, NSAIDs, opioids, corticosteroids and agents modulating the central neuronal activity (TRPV1 antagonists) may be used, depending on the underlying comorbidity. For moderate-to-severe pain, a combination of opioids and nonopioids could offer optimal pain relief. In cases of pain from trauma or surgical procedures, systemic medication would have to be administered.

\section{- Chronic pain}

Management goals for chronic pain include reducing the suffering due to pain and the associated emotional distress, in addition to increasing the coping ability and psychosocial well-being of the patient, by targeting the hypersensitive nervous system. ${ }^{205}$ Multimodal therapy involving a combination of treatments is recommended for treatment of chronic cancer or noncancer pain. The treatment for CNCP could include nonopioids (paracetamol, NSAIDs and selective COX-2 inhibitors), opioids, analgesics, TCAs, corticosteroids, muscle relaxants, sedatives and anxiolytics.

\section{- Nociceptive pain}

Nociceptive pain is generally time limited as the pain resolves when the tissue damage heals, but it may also be persistent when associated with inflammatory disorders such as rheumatoid arthritis. Treatment for localized pain should be started with the use of topical or oral NSAIDs. ${ }^{56}$ Moderate-to-severe pain unresponsive to NSAIDs may be treated with opioids to manage symptoms and control inflammation. ${ }^{206}$ Additionally, corticosteroids and immune-modulating agents (biologics) can also be used to manage inflammation in arthritic pain. ${ }^{207}$
- Neuropathic pain

Peripheral neuropathic pain manifests as stimulusindependent pain or stimulus-evoked pain (pain hypersensitivity triggered by a stimulus following damage to sensory neurons). Neuropathic pain may persist for months or years beyond the normal healing time of any damaged tissues. Evidence from randomized controlled studies (RCTs) and systematic reviews have confirmed the efficacy of TCAs (amitriptyline and nortriptyline), antiseizure medications (pregabalin, gabapentin and carbamazepine) and opioids in the treatment of various neuropathic conditions. ${ }^{85,86,208-212}$ Evidence supports the use of opioids as second- or third-line therapies for neuropathic pain, particularly of peripheral origin (Table S1) (A). ${ }^{208,209}$ However, further confirmation from well-controlled studies is warranted to establish the efficacy of these agents in complex neuropathies. ${ }^{189,213}$

- Mild, moderate and severe pain

Treatment recommendations are also dependent on the severity of pain. Acetaminophen and other mild NSAIDs such as aspirin are the preferred treatment for mild chronic pain and may be used to supplement other agents in treating mild-to-moderate pain. ${ }^{56}$ However, acetaminophen lacks anti-inflammatory effects, limiting its use in pain associated with inflammatory diseases such as arthritis. NSAIDs are recommended for periodic flare-ups of mild-to-moderate inflammatory or nonneuropathic pain. For management of persistent moderate-to-severe pain, opioid therapy is the most sought-after treatment. Opioids are considered effective in the treatment of neuropathic pain that is not responsive to initial therapies, but not in the treatment of inflammatory, mechanical or compressive pain. Certain strong opioids, however, do not necessarily improve functional or psychological status and should be administered under adequate supervision. ${ }^{214-216}$

A person's experience of pain generally manifests itself in emotional and behavioral responses and is strongly correlated to the culture, personal history and perceptions of the individual. ${ }^{130}$ Thus, treatment for pain must be tailored for each individual patient and should focus on interruption of reinforcement of the pain behavior and modulation of the pain response. Important factors to be considered for treatment recommendation include individual's response to prior appropriate treatment management, compliance and drug abuse/dependence behavior. ${ }^{56}$ An understanding of cultural-based attitudes about pain is critical in the management of pain. 


\section{Treatment in special populations}

Undertreatment of pain in special populations, such as the elderly, children or patients with renal/hepatic impairment, results from inadequate pain assessment and efficacy issues. Pain treatment in these populations must be performed following careful consideration of adverse events and the pharmacokinetic profile of the analgesic.

\section{Elderly}

Studies report that the prevalence of pain is higher in the elderly population, with high proportion of patients with disability and poor QoL. ${ }^{62,217}$ The most commonly occurring pain conditions in the elderly are rheumatoid or osteoarthritis, cancer and diabetic neuropathy. ${ }^{218}$ In addition, elderly patients with chronic pain present several clinical comorbidities, which may influence the outcome of pain therapy. These may include gastrointestinal/renal/hepatic dysfunction, depression, anxiety and cognitive impairment, among others. ${ }^{219,220}$ Due to the limited evidence from clinical studies on the geriatric population with pain, ${ }^{221}$ the health care practitioner needs to evaluate the possible risk factors that may impede effective analgesia. NSAIDs should be avoided in such patients due to the potential for gastrointestinal bleeding and renal toxicity. Opioids such as morphine, codeine, fentanyl or oxycodone may cause constipation or respiratory depression and should be used with caution, preferably in low doses and along with laxatives. ${ }^{222}$ Paracetamol is the analgesic of choice for the geriatric population with pain.

\section{Children}

Pain in children may be mostly due to injuries, burns, inflammation and chronic illnesses such as cancer, HIV/AIDS or postoperative status. The WHO guidelines on management of chronic pain in children emphasize the importance of pain assessment in children. ${ }^{223}$ Since self-reports of pain severity cannot be obtained in infants or small children, pain assessment entirely depends upon the clinician's reports. Symptoms of crying, agitation, irritation or facial expression may be indicative of pain in infants. For children $>4$ years of age, Faces Pain Scale may be used for pain assessment. ${ }^{224,225}$ Pharmacological therapy of pain in children should take into account the age, pain intensity, underlying disease or comorbidities as well as the functional ability. The first-line therapy generally includes safer analgesics such as paracetamol, followed by ibuprofen. ${ }^{223}$ The second-line therapy may include other NSAIDs. Strong opioids should only be used in moderate-to-severe pain. ${ }^{226}$ The most preferred route of medication administration should be oral, either as tablets or as syrups. ${ }^{134}$

\section{Pregnant and lactating women}

During pregnancy, women may experience LBP, joint pain, as well as abdominal and pelvic pain, among other conditions. Analgesic treatment during pregnancy and lactation may be difficult considering certain medications can potentially harm the fetus or may pass through breast milk and affect a nursing infant. Administration of NSAIDs in the first trimester has been linked to premature ductal closure and should be avoided. ${ }^{227}$ Aspirin may be used in the first trimester but should be avoided near term, as it may delay labor and cause hemostatic abnormalities. ${ }^{228}$ Paracetamol and opioids are relatively safer analgesics to use in pregnant women. In the case of lactating women, paracetamol and NSAIDs may be safe to use, while opioids should be avoided due to the risk of toxicity and dependence. ${ }^{229}$

\section{Renal impairment}

A majority of analgesics are excreted by the renal route, and it is important to assess kidney function prior to administering analgesics for chronic pain. Since impaired renal function may lead to accumulation of drugs, there are chances of toxicity in such patients. Clinicians should conduct adequate assessment of kidney function by estimating serum creatinine values and the estimated glomerular filtration rate (eGFR). ${ }^{203} \mathrm{An}$ eGFR of $<60 \mathrm{~mL} / \mathrm{min} / 1.73 \mathrm{~m}^{2}$ may warrant dose adjustment. ${ }^{230}$ NSAIDs, such as indomethacin, naproxen, diclofenac and ibuprofen, have been shown to decrease the GFR and increase the possibility of edema due to prostaglandin-mediated inhibition of renin. ${ }^{231}$ Therefore, NSAIDs are best avoided in patients with renal impairment. Alternatives to NSAIDs are paracetamol and opioids such as codeine, tramadol or buprenorphine, ${ }^{232}$ morphine and codeine are undialyzable and should be avoided in patients who are undergoing hemodialysis. ${ }^{231}$ For moderate-to-severe pain, fentanyl can be safely administered to patients with renal dysfunction or those who require dialysis (although caution needs to be exercised in such patients as fentanyl is poorly dialyzable). ${ }^{232,233}$

\section{Liver failure}

Deciding analgesic therapy for patients with hepatic impairment can be a challenge, since most analgesics undergo hepatic metabolism. Cirrhosis is the most prevalent manifestation of liver disease, and it may be caused due to excessive alcohol intake, hepatitis infection or drug-induced toxicity. Since liver is the main site of metabolism for paracetamol, NSAIDs and opioids such as morphine, its dysfunction may lead to increased blood levels of these drugs, particularly those that are primarily metabolized by cytochrome P450 
(CYP) enzymes. ${ }^{234}$ On the contrary, changes in CYP enzymes may result in decreased efficacy of codeine and tramadol, which undergo biotransformation to active metabolites. ${ }^{235}$ Thus, a thorough understanding of the pharmacokinetic profile of analgesics may help in deciding the appropriate pharmacotherapy for patients with liver dysfunction. ${ }^{236}$ For instance, although paracetamol undergoes metabolic conversion to a hepatotoxic metabolite $\mathrm{N}$-acetyl-p-benzoquinone imine, ${ }^{237}$ clinically significant toxicity is observed only at large doses, and small doses of this drug may appear to be safe in such patients. ${ }^{238}$ Dose adjustment should be considered while administering NSAIDs and opioids to patients with hepatic impairment.

Disease-specific treatment recommendations are presented in the Supplementary materials section.

\section{Acknowledgments}

We wish to acknowledge the efforts of other members of the Pain Working Group who contributed significantly to the development of this manuscript, namely, SS Sukumar, Hammad Usmani, Rajeev Rao, Ananth Hazare, PR Krishnan, Poorna Chandra and Umesh Gupta. Padmini Deshpande (Siro Clinpharm Pvt Ltd) provided writing assistance, and $\mathrm{Dr}$ Sangita Patil (SIRO Clinpharm Pvt Ltd) provided additional editorial support for the development of this manuscript. This study was funded by Johnson \& Johnson Pvt Ltd, Mumbai, Maharashtra, India.

\section{Author contributions}

All authors contributed towards drafting and critically revising the review and agree to be accountable for all aspects of the work. All authors met International Committee of Medical Journal Editors criteria and all those who fulfilled those criteria are listed as authors. All authors provided direction and comments on the manuscript, made the final decision about where to publish as well as approved the submission of the manuscript to the journal.

\section{Disclosure}

Prashant Narang and Jaishid Ahdal are employees and/or shareholders of Johnson \& Johnson Private Limited, Mumbai, Maharashtra, India. Gur Prasad Dureja, Rajagopalan N Iyer, and Gautam Das report no conflicts of interest in this work.

\section{References}

1. International Association for the Study of Pain [webpage on the Internet]. (IASP) Taxonomy; 2012. Available from: http://www.iasp-pain. org/Taxonomy. Accessed April 2016.
2. Goldberg DS, McGee SJ. Pain as a global public health priority. $B M C$ Public Health. 2011;11:770.

3. McPhillips-Tangum CA, Cherkin DC, Rhodes LA, Markham C. Reasons for repeated medical visits among patients with chronic back pain. J Gen Intern Med. 1998;13(5):289-295.

4. Mäntyselkä P, Kumpusalo E, Ahonen R, et al. Pain as a reason to visit the doctor: a study in Finnish primary health care. Pain. 2001;89(2-3):175-180.

5. Moore RJ. Biobehavioral Approaches to Pain. Berlin: Springer; 2009.

6. Gregory J, McGowan L. An examination of the prevalence of acute pain for hospitalised adult patients: a systematic review. J Clin Nurs. 2016;25(5-6):583-598.

7. Murphy A, McCoy S, O'Reilly K, et al. A prevalence and management study of acute pain in children attending emergency departments by ambulance. Prehosp Emerg Care. 2016;20(1):52-58.

8. Galinski M, Ruscev M, Gonzalez G, et al. Prevalence and management of acute pain in prehospital emergency medicine. Prehosp Emerg Care. 2010;14(3):334-339.

9. Gatchel RJ, Turk DC. Psychosocial Factors in Pain: Critical Perspectives. New York, NY: Guilford Press; 1999.

10. Jackson TP, Stabile VS, McQueen KK. The global burden of chronic pain. ASA Newsl. 2014;78:24-27.

11. Butchart A, Kerr EA, Heisler M, Piette JD, Krein SL. Experience and management of chronic pain among patients with other complex chronic conditions. Clin J Pain. 2009;25(4):293-298.

12. Bouhassira D, Lantéri-Minet M, Attal N, Laurent B, Touboul C. Prevalence of chronic pain with neuropathic characteristics in the general population. Pain. 2008;136(3):380-387.

13. Torrance N, Smith BH, Bennett MI, Lee AJ. The epidemiology of chronic pain of predominantly neuropathic origin. Results from a general population survey. J Pain. 2006;7(4):281-289.

14. Van Hecke O, Austin SK, Khan RA, Smith B, Torrance N. Neuropathic pain in the general population: a systematic review of epidemiological studies. Pain. 2014;155(4):654-662.

15. Mäntyselkä PT, Turunen JH, Ahonen RS, Kumpusalo EA. Chronic pain and poor self-rated health. JAMA. 2003;290(18):2435-2442.

16. Torrance N, Elliott AM, Lee AJ, Smith BH. Severe chronic pain is associated with increased 10 year mortality. A cohort record linkage study. Eur J Pain. 2010;14(4):380-386.

17. Facts and Figures on Pain. American Academy of Pain Medicine. Available from: http://www.painmed.org/files/facts-and-figures-onpain.pdf. Accessed April 2016.

18. Breivik H, Eisenberg E, O'Brien T, OPENMinds. The individual and societal burden of chronic pain in Europe: the case for strategic prioritisation and action to improve knowledge and availability of appropriate care. BMC Public Health. 2013;13(1):1229.

19. Gaskin DJ, Richard P. The economic costs of pain in the United States. J Pain. 2012;13(8):715-724.

20. Bond M. Pain education issues in developing countries and responses to them by the International Association for the Study of Pain. Pain Res Manag. 2011;16(6):404-406.

21. Institute for Health Metrics and Evaluation. Global burden of diseases, injuries, and risk factors study 2010: India. Institute for Health Metrics and Evaluation; 2013. Available from: http://www.healthdata. org/sites/default/files/files/country_profiles/GBD/ihme_gbd_country_report_india.pdf. Accessed April 2016.

22. hrw.org. Global state of pain treatment - access to medicines and palliative care. The Human Rights Watch; 2011. Available from: https:// www.hrw.org/sites/default/files/reports/hhr0511W.pdf. Accessed April 2016.

23. Dureja GP, Jain PN, Shetty N, et al. Prevalence of chronic pain, impact on daily life, and treatment practices in India. Pain Pract. 2014;14(2):E51-E62.

24. Srinath Reddy K, Shah B, Varghese C, Ramadoss A. Responding to the threat of chronic diseases in India. Lancet. 2005;366(9498): 1744-1749.

25. Patel V, Chatterji S, Chisholm D, et al. Chronic diseases and injuries in India. Lancet. 2011;377(9763):413-428. 
26. Abdulla A, Adams N, Bone M, et al. Guidance on the management of pain in older people. Age Ageing. 2013;42(suppl 1):i1-i57.

27. Ferrell BA. Pain management in elderly people. J Am Geriatr Soc. 1991;39(1):64-73.

28. Tsang A, Von Korff M, Lee S, et al. Common chronic pain conditions in developed and developing countries: gender and age differences and comorbidity with depression-anxiety disorders. J Pain. 2008;9(10):883-891.

29. American Geriatrics Society Panel on Pharmacological Management of Persistent Pain in Older Persons. Pharmacological management of persistent pain in older persons. American geriatrics society panel on the pharmacological management of persistent pain in older persons. Pain Med. 2009;10(6):1062-1083.

30. Herr KA, Garand L. Assessment and measurement of pain in older adults. Clin Geriatr Med. 2001;17(3):457-478.

31. Visser AW, Boyesen P, Haugen IK, et al. Instruments measuring pain, physical function, or patient's global assessment in hand osteoarthritis: a systematic literature search. J Rheumatol. 2015;42(11):2118-2134.

32. Smith JP, Majmundar M. Aging in Asia: Findings from New and Emerging Data Initiatives. Washington, DC: National Academies Press; 2012.

33. Golechha M. Healthcare agenda for the Indian government. Indian J Med Res. 2015;141(2):151-153.

34. Maheshwari RW, Chincholkar A, Gupta M. Prescription pattern monitoring of non-steroidal anti-inflammatory drugs in urban health center in Talegaon: a retrospective study. IJPBS. 2015;6:596-602.

35. Gupta M, Malhotra S, Jain S, Aggarwal A, Pandhi P. Pattern of prescription of non-steroidal antiinflammatory drugs in orthopaedic outpatient clinic of a north Indian tertiary care hospital. Indian J Pharmacol. 2005;37(6):404.

36. Jain N, Jain S. Symposium: pain management: current trends. JIMSA. 2013;26(4):243-244.

37. Khade A, Bashir MSM, Sheethal A. Prescription pattern in the department of surgery in a tribal district hospital of Andhra Pradesh, India. Ann Med Health Sci Res. 2013;3(3):438-441.

38. Patel V, Vaidya R, Naik D, Borker P. Irrational drug use in India: a prescription survey from Goa. J Postgrad Med. 2005;51(1):9.

39. Shalini M, Joshi M. Study of polypharmacy and associated problems among elderly patients. Internet J Med Update. 2012;7(1):35-39.

40. Bhatnagar S. Freedom from pain (Sixteenth International Conference of Indian Association of Palliative Care). Caregiver Burden of Chronic Pain in India. New Delhi: I. K. International Pvt Ltd; 2009.

41. Zallman L, Rubens SL, Saitz R, Samet JH, Lloyd-Travaglini C, Liebschutz J. Attitudinal barriers to analgesic use among patients with substance use disorders. Pain Res Treat. 2012;2012:167062.

42. Von Roenn JH, Cleeland CS, Gonin R, Hatfield AK, Pandya KJ. Physician attitudes and practice in cancer pain management: a survey from the Eastern Cooperative Oncology Group. Ann Intern Med. 1993;119(2):121-126.

43. University of Minnesota [webpage on the Internet]. Levels of evidence and grades of recommendations. University of Minnesota: National Guidelines Clearinghouse. Available from: https:/hsl.lib.umn.edu/ biomed/help/levels-evidence-and-grades-recommendations. Accessed May 2016.

44. Besson J. The complexity of physiopharmacologic aspects of pain. Drugs. 1996;53(2):1-9.

45. Jensen TS, Baron R. Translation of symptoms and signs into mechanisms in neuropathic pain. Pain. 2003;102(1-2):1-8.

46. Baron R. Mechanisms of disease: neuropathic pain - a clinical perspective. Nat Clin Pract Neurol. 2006;2(2):95-106.

47. Bridges D, Thompson SWN, Rice ASC. Mechanisms of neuropathic pain. Br J Anaesth. 2001;87(1):12-26.

48. Nickel FT, Seifert F, Lanz S, Maihöfner C. Mechanisms of neuropathic pain. Eur Neuropsychopharmacol. 2012;22(2):81-91.

49. Hansson PT, Dickenson AH. Pharmacological treatment of peripheral neuropathic pain conditions based on shared commonalities despite multiple etiologies. Pain. 2005;113(3):251-254.
50. Treede R-D, Jensen TS, Campbell J, et al. Neuropathic pain redefinition and a grading system for clinical and research purposes. Neurology. 2008;70(18):1630-1635.

51. Sussman C, Bates-Jensen BM. Wound Care: A Collaborative Practice Manual. 3rd ed. Philadelphia, PA: Lippincott Williams \& Wilkins; 2007.

52. Fallon MT. Neuropathic pain in cancer. Br J Anaesth. 2013;111(1): 105-111.

53. Baron R, Binder A. How neuropathic is sciatica? The mixed pain concept. Orthopade. 2004;33(5):568-575.

54. Campbell JN, Meyer RA. Mechanisms of neuropathic pain. Neuron. 2006;52(1):77-92.

55. Bonica JJ. Neurophysiologic and pathologic aspects of acute and chronic pain. Arch Surg. 1977;112(6):750-761.

56. Hooten W, Timming R, Belgrade M, et al. Assessment and Management of Chronic Pain. Bloomington, MN: Institute for Clinical Systems Improvement; 2013:106.

57. Berry P, Chapman C, Covington E, et al. Pain: Current Understanding of Assessment, Management, and Treatments. Reston, VA: National Pharmaceutical Council and the Joint Commission for the Accreditation of Healthcare Organizations; 2001:b44.

58. Ashburn MA, Staats PS. Management of chronic pain. Lancet. 1999;353(9167):1865-1869.

59. Henry JL. Pathophysiology of Chronic Pain; 2008. Available from: http://fhs.mcmaster.ca/paininstitute/documents/pathophysiology_of_ chronic_pain.pdf. Accessed May 2016.

60. Portenoy RK, Hagen NA. Breakthrough pain: definition, prevalence and characteristics. Pain. 1990;41(3):273-281.

61. Mishra S, Bhatnagar S, Chaudhary P, Rana SPS. Breakthrough cancer pain: review of prevalence, characteristics and management. Indian J Palliat Care. 2009;15(1):14-18.

62. van den Beuken-van Everdingen M, de Rijke J, Kessels A, Schouten H, van Kleef M, Patijn J. Prevalence of pain in patients with cancer: a systematic review of the past 40 years. Ann Oncol. 2007;18(9): 1437-1449.

63. Foley K. Pain syndromes in patients with cancer. In: Swerdlow M, Ventafridda V, editors. Cancer Pain. Netherlands: Springer; 1987:45-54.

64. Wall PD, Melzack R, Bonica JJ. Textbook of Pain. Edinburgh: Churchill Livingstone; 1994

65. International Association for the Study of Pain (IASP). Breakthrough pain in cancer patients; 2006. Available from: http://iasp.files.cms-plus. com/Content/ContentFolders/Publications2/PainClinicalUpdates/ Archives/PCU06-1_1390263807201_21.pdf. Accessed May 2016.

66. Juska M, Balon R. Chronic non-cancer pain and substance use disorders: challenges and strategies. Curr Psychiatry. 2013;12(7):35-41.

67. Ho KY, Chua N, George JM, et al. Evidence-based guidelines on the use of opioids in chronic non-cancer pain - a consensus statement by the Pain Association of Singapore Task Force. Ann Acad Med Singapore. 2013;42(3):138-152.

68. Kahan M, Mailis-Gagnon A, Wilson L, Srivastava A; National Opioid Use Guideline Group. Canadian guideline for safe and effective use of opioids for chronic noncancer pain clinical summary for family physicians. Part 1: general population. Can Fam Physician. 2011;57(11):1257-1266.

69. Pain C. Pain management: classifying, understanding, and treating pain. Hosp Physician. 2002;38(6):23-30.

70. Iasp-pain.org. International Association for the Study of Pain (IASP): Classification of chronic pain; 2002. Available from: http://www. iasp-pain.org/files/Content/ContentFolders/Publications2/FreeBooks/ Classification-of-Chronic-Pain.pdf. Accessed May 2016.

71. World Health Organization. WHO guidelines on pharmacological treatment of persisting pain in children with medical illnesses; 2012. Available from: http://apps.who.int/iris/bitstream/10665/44540/1/9789241548120_ Guidelines.pdf. Accessed May 2016.

72. Murphy MP. Somatic pain. In: Schmidt FR, Willis DW, editors. Encyclopedia of Pain. Berlin, Heidelberg: Springer Berlin Heidelberg; 2007:2190-2192. 
73. Woolf C. Somatic pain-pathogenesis and prevention. Br J Anaesth. 1995;75(2):169-176.

74. Giamberardino MA. Visceral Pain: Clinical, Pathophysiological and Therapeutic Aspects. Oxford: Oxford University Press; 2009.

75. Davis MP. Drug management of visceral pain: concepts from basic research. Pain Res Treat. 2012;2012:18.

76. Vecchiet L, Vecchiet J, Giamberardino MA. Referred muscle pain: clinical and pathophysiologic aspects. Curr Rev Pain. 1999;3(6):489-498.

77. Giamberardino MA. Referred muscle pain/hyperalgesia and central sensitisation. J Rehabil Med Suppl. 2003;1(Suppl 41):85-88

78. Treede RD, Rief W, Barke A, et al. A classification of chronic pain for ICD-11. Pain. 2015;156(6):1003-1007.

79. Woolf C. Recent advances in the pathophysiology of acute pain. $\mathrm{Br} J$ Anaesth. 1989;63(2):139-146.

80. Woolf CJ. Central sensitization: implications for the diagnosis and treatment of pain. Pain. 2011;152(3 suppl):S2-S15.

81. Kidd B, Urban L. Mechanisms of inflammatory pain. Br J Anaesth. 2001;87(1):3-11.

82. Rocha APC, Kraychete DC, Lemonica L, et al. Pain: current aspects on peripheral and central sensitization. Rev Bras Anestesiol. 2007;57(1):94-105.

83. Latremoliere A, Woolf CJ. Central sensitization: a generator of pain hypersensitivity by central neural plasticity. J Pain. 2009;10(9): 895-926.

84. Marks DM, Shah MJ, Patkar AA, Masand PS, Park G-Y, Pae C-U. Serotonin-norepinephrine reuptake inhibitors for pain control: premise and promise. Curr Neuropharmacol. 2009;7(4):331-336.

85. Sindrup SH, Otto M, Finnerup NB, Jensen TS. Antidepressants in the treatment of neuropathic pain. Basic Clin Pharmacol Toxicol. 2005;96(6):399-409.

86. Jensen TS. Anticonvulsants in neuropathic pain: rationale and clinical evidence. Eur J Pain. 2002;6(suppl A):61-68.

87. Schaible H-G. Peripheral and central mechanisms of pain generation. In: Stein C, editor. Analgesia. Berlin: Springer Berlin Heidelberg; 2006:3-28.

88. Cross SA. Pathophysiology of pain. Mayo Clinic Proc. 1994;69(4): 375-383.

89. Petrenko AB, Yamakura T, Baba H, Shimoji K. The role of N-methylD-aspartate (NMDA) receptors in pain: a review. Anesth Analg. 2003;97(4):1108-1116.

90. Fein A. Nociceptors and the Perception of Pain. Vol. 4. Farmington, CT: University of Connecticut Health Center; 2012;4:61-67.

91. Puretić MB, Demarin V. Neuroplasticity mechanisms in the pathophysiology of chronic pain. Acta Clin Croat. 2012;51(2):1.

92. Basbaum AI, Fields HL. Endogenous pain control mechanisms: review and hypothesis. Ann Neurol. 1978;4(5):451-462.

93. Ossipov MH, Dussor GO, Porreca F. Central modulation of pain. J Clin Invest. 2010;120(11):3779-3787.

94. Sinatra R. Causes and consequences of inadequate management of acute pain. Pain Med. 2010;11(12):1859-1871.

95. Pergolizzi JV, Raffa RB, Taylor R. Treating acute pain in light of the chronification of pain. Pain Manag Nurs. 2014;15(1):380-390.

96. Voscopoulos C, Lema M. When does acute pain become chronic? Br J Anaesth. 2010;105(suppl 1):i69-i85.

97. Siddall PJ. Neuroplasticity and pain: what does it all mean? Med $J$ Aust. 2013;198(4):177-178.

98. Ray AL. Neuroplasticity, sensitization, and pain. Treatment of Chronic Pain by Integrative Approaches: the AMERICAN ACADEMY of PAIN MEDICINE Textbook on Patient Management. Deer TR, Leong Michael S, Ray AL, eds. Springer; 2013:759-768.

99. May A. Chronic pain may change the structure of the brain. Pain. 2008;137(1):7-15.

100. Dworkin RH. Toward a clearer specification of acute pain risk factors and chronic pain outcomes. Pain Forum. 1997;6(2):148-150.

101. Young Casey C, Greenberg MA, Nicassio PM, Harpin RE, Hubbard D. Transition from acute to chronic pain and disability: a model including cognitive, affective, and trauma factors. Pain. 2008;134(1-2):69-79.
102. Dworkin RH. Which individuals with acute pain are most likely to develop a chronic pain syndrome? Pain Forum. 1997;6(2): 127-136.

103. van der Windt DA, Kuijpers T, Jellema P, van der Heijden GJ, Bouter LM. Do psychological factors predict outcome in both low-back pain and shoulder pain? Ann Rheum Dis. 2007;66(3):313-319.

104. Hunter J. Physical symptoms and signs and chronic pain. Clin J Pain. 2001;17(4 suppl):S26-S32.

105. Breivik H, Collett B, Ventafridda V, Cohen R, Gallacher D. Survey of chronic pain in Europe: prevalence, impact on daily life, and treatment. Eur J Pain. 2006;10(4):287-333.

106. World Health Organization. Achieving balance in national opioids control policy: guidelines for assessment; 2000. Available from: http:// apps.who.int/medicinedocs/pdf/whozip39e/whozip39e.pdf. Accessed May 2016.

107. Andersson HI. Increased mortality among individuals with chronic widespread pain relates to lifestyle factors: a prospective populationbased study. Disabil Rehabil. 2009;31(24):1980-1987.

108. Macfarlane GJ, Crombie IK, McBeth J, Silman AJ. Widespread body pain and mortality: prospective population based study. Commentary: an interesting finding, but what does it mean? BMJ. 2001;323(7314):662.

109. Cleary J, Simha N, Panieri A, et al. Formulary availability and regulatory barriers to accessibility of opioids for cancer pain in India: a report from the Global Opioid Policy Initiative (GOPI). Ann Oncol. 2013;24(suppl 11):xi33-xi40.

110. Berterame S, Erthal J, Thomas J, et al. Use of and barriers to access to opioid analgesics: a worldwide, regional, and national study. Lancet. 2016;387(10028):1644-1656.

111. LeBaron V, Beck SL, Maurer M, Black F, Palat G. An ethnographic study of barriers to cancer pain management and opioid availability in India. Oncologist. 2014;19(5):515-522.

112. Vane J, Bakhle Y, Botting R. Cyclooxygenases 1 and 2. Annu Rev Pharmacol Toxicol. 1998;38(1):97-120.

113. Rao P, Knaus EE. Evolution of nonsteroidal anti-inflammatory drugs (NSAIDs): cyclooxygenase (COX) inhibition and beyond. $J$ Pharm Pharm Sci. 2008;11(2):81s-110s.

114. healthbrk.com/ [webpage on the Internet]. Acetaminophen. The new world encylopedia;2016. Available from: http://healthbrk.com/healthproblems/drug/10503-acetaminophen-new-world-encyclopedia. Accessed May 2016.

115. Hawkey CJ. COX-2 chronology. Gut. 2005;54(11):1509-1514.

116. Bannwarth B, Kostine M. Targeting nerve growth factor (NGF) for pain management: what does the future hold for NGF antagonists? Drugs. 2014;74(6):619-626.

117. Wong GY, Gavva NR. Therapeutic potential of vanilloid receptor TRPV1 agonists and antagonists as analgesics: recent advances and setbacks. Brain Res Rev. 2009;60(1):267-277.

118. Bair MJ, Robinson RL, Katon W, Kroenke K. Depression and pain comorbidity: a literature review. Arch Intern Med. 2003;163(20): 2433-2445.

119. Sansone RA, Sansone LA. Pain, pain, go away: antidepressants and pain management. Psychiatry (Edgmont). 2008;5(12):16-19.

120. Ryder S-A, Stannard CF. Treatment of chronic pain: antidepressant, antiepileptic and antiarrhythmic drugs. Contin Educ Anaesth Crit Care Pain. 2005;5(1):18-21.

121. WHO. Cancer Pain Relief: with a Guide to Opioid Availability. Geneva, Switzerland: WHO; 1996.

122. Vargas-Schaffer G. Is the WHO analgesic ladder still valid? Twentyfour years of experience. Can Fam Physician. 2010;56(6):514-517.

123. Chou R, Huffman LH, American Pain Society, American College of Physicians. Nonpharmacologic therapies for acute and chronic low back pain: a review of the evidence for an American pain society/ American college of physicians clinical practice guideline. Ann Intern Med. 2007;147(7):492-504.

124. Wright A, Sluka KA. Nonpharmacological treatments for musculoskeletal pain. Clin J Pain. 2001;17(1):33-46. 
125. Bronfort G, Evans R, Nelson B, Aker PD, Goldsmith CH, Vernon H. A randomized clinical trial of exercise and spinal manipulation for patients with chronic neck pain. Spine. 2001;26(7):788-797.

126. Chiu TT, Hui-Chan CW, Cheing G. A randomized clinical trial of TENS and exercise for patients with chronic neck pain. Clin Rehabil. 2005; 19(8):850-860.

127. Sherman KJ, Cherkin DC, Erro J, Miglioretti DL, Deyo RA. Comparing yoga, exercise, and a self-care book for chronic low back pain: a randomized, controlled trial. Ann Intern Med. 2005;143(12):849-856.

128. Walker MJ, Boyles RE, Young BA, et al. The effectiveness of manual physical therapy and exercise for mechanical neck pain: a randomized clinical trial. Spine. 2008;33(22):2371-2378.

129. Ylinen J, Takala E, Nykänen M, et al. Active neck muscle training in the treatment of chronic neck pain in women: a randomized controlled trial. JAMA. 2003;289(19):2509-2516.

130. Fortier MA, Anderson CT, Kain ZN. Ethnicity matters in the assessment and treatment of children's pain. Pediatrics. 2009;124(1): 378-380.

131. Campbell CM, Edwards RR. Ethnic differences in pain and pain management. Pain Manag. 2012;2(3):219-230.

132. Callister LC. Cultural influences on pain perceptions and behaviors. Home Health Care Manag Pract. 2003;15(3):207-211.

133. Shipton E. The pain experience and sociocultural factors. New Zealand Med J. 2013;126(1370):7-9.

134. Diatchenko L, Slade GD, Nackley AG, et al. Genetic basis for individual variations in pain perception and the development of a chronic pain condition. Hum Mol Gen. 2005;14(1):135-143.

135. Nielson WR, Weir R. Biopsychosocial approaches to the treatment of chronic pain. Clin J Pain. 2001;17(4 suppl):S114-S127.

136. Ferrari R, Schrader H. The late whiplash syndrome: a biopsychosocial approach. J Neurol Neurosurg Psychiatry. 2001;70(6):722-726.

137. Kim H, Dionne RA. Individualized pain medicine. Drug Discov Today Ther Strateg. 2009;6(3):83-87.

138. Nature Publishing Group [webpage on the Internet]. Combination Drug Therapy; 2016. Available from: http://www.nature.com/subjects/combination-drug-therapy?WT.ac=search_subjects_combination_drug_therapy. Accessed May 2016.

139. Straube A, Aicher B, Fiebich BL, Haag G. Combined analgesics in (headache) pain therapy: shotgun approach or precise multi-target therapeutics? BMC Neurol. 2011;11(1):1-15.

140. World Health Organization. Guidelines for registration of fixed-dose combination medicinal products. Technical Report Series; 2005. Available from: http://apps.who.int/medicinedocs/documents/s19979en/ s19979en.pdf. Accessed May 2016.

141. Goswami N, Gandhi A, Patel P, Dikshit R. An evaluation of knowledge, attitude and practices about prescribing fixed dose combinations among resident doctors. Perspect Clin Res. 2013;4(2):130.

142. Sibal V, Raju S, Mondal M, Ahmad MN. Combination drugs: are they rational? Curr Sci. 2006;91(4):406.

143. Gautam CS, Saha L. Fixed dose drug combinations (FDCs): rational or irrational: a view point. Br J Clin Pharmacol. 2008;65(5): 795-796.

144. The Indian Express [webpage on the Internet]. Complete list: Do you take one of these 300 banned drug combinations? 2016. Available from: http://indianexpress.com/article/india/india-news-india/do-youtake-one-of-these-300-banned-drugs/. Accessed June 2016.

145. US Food and Drug Administration. Guidance for industry Analgesic Indications: developing drug and biological products; 2014. Available from: http://www.fda.gov/downloads/drugs/guidancecomplianceregulatoryinformation/guidances/ucm384691.pdf. Accessed June 2016.

146. Central Drugs Standard Control Organization. Guidance for industry on fixed dose combinations (FDCs); 2010. Available from: http://www. cdsco.nic.in/writereaddata/FDC\%20Guidelines\%20_\%20Revised1. pdf. Accessed June 2016.

147. Central Drugs Standard Control Organization (CDSCO). List of approved Fixed Drug Combinations (FDCs) in India. Available from: http://cdsco.nic.in/writereaddata/SND-Approval-Drugs-mayList1-2016.pdf. Accessed June 2016.
148. MacDonald N, Findlay HP, Bruera E, Dudgeon D, Kramer J. A Canadian survey of issues in cancer pain management. J Pain Symptom Manag. 1997;14(6):332-342.

149. Sapir R, Catane R, Strauss-Liviatan N, Cherny NI. Cancer pain: knowledge and attitudes of physicians in Israel. J Pain Symptom Manag. 1999;17(4):266-276.

150. Yu S, Wang XS, Cheng Y, Yang J, Cleeland CS. Special aspects of cancer pain management in a Chinese general hospital. Eur J Pain. 2001;5(suppl A): 15-20.

151. Vainio A. Treatment of terminal cancer pain in France: a questionnaire study. Pain. 1995;62(2):155-162.

152. Ensink FB, Bautz MT, Voss MC, Gorlitz A, Hanekop GG. [Indicators of structural quality in palliative care for cancer pain patients in Lower-Saxony]. Schmerz. 2002;16(4):255-262.

153. Elliott TE, Elliott BA. Physician attitudes and beliefs about use of morphine for cancer pain. J Pain Symptom Manag. 1992;7(3):141-148.

154. Greenwald BD, Narcessian EJ, Pomeranz BA. Assessment of physiatrists' knowledge and perspectives on the use of opioids: review of basic concepts for managing chronic pain. Am J Phys Med Rehabil. 1999;78(5):408-415.

155. Anderson KO, Richman SP, Hurley J, et al. Cancer pain management among underserved minority outpatients: perceived needs and barriers to optimal control. Cancer. 2002;94(8):2295-2304.

156. Wolfert MZ, Gilson AM, Dahl JL, Cleary JF. Opioid analgesics for pain control: wisconsin physicians' knowledge, beliefs, attitudes, and prescribing practices. Pain Med. 2010;11(3):425-434.

157. Ripamonti C, Bandieri E, Roila F; ESMO Guidelines Working Group. Management of cancer pain: ESMO clinical practice guidelines. Ann Oncol. 2011;22(Suppl 6):vi69-vi77.

158. Chou R, Fanciullo GJ, Fine PG, et al. Clinical guidelines for the use of chronic opioid therapy in chronic noncancer pain. $J$ Pain. 2009;10(2):113-130.

159. Trescot AM, Boswell MV, Atluri SL, et al. Opioid guidelines in the management of chronic non-cancer pain. Pain Physician. 2006;9(1):1-39.

160. Tournebize J, Gibaja V, Muszczak A, Kahn JP. Are physicians safely prescribing opioids for chronic noncancer pain? A systematic review of current evidence. Pain Pract. 2016;16(3):370-383.

161. Bhamb B, Brown D, Hariharan J, Anderson J, Balousek S, Fleming MF. Survey of select practice behaviors by primary care physicians on the use of opioids for chronic pain. Curr Med Res Opin. 2006;22(9):1859-1865.

162. Cleeland CS, Janjan NA, Scott CB, Seiferheld WF, Curran WJ. Cancer pain management by radiotherapists: a survey of radiation therapy oncology group physicians. Int J Radiat Oncol Biol Phys. 2000;47(1):203-208.

163. Jacobsen R, Moldrup C, Christrup L, Sjogren P. Patient-related barriers to cancer pain management: a systematic exploratory review. Scand $J$ Caring Sci. 2009;23(1):190-208.

164. Elliott BA, Elliott TE, Murray DM, Braun BL, Johnson KM. Patients and family members: the role of knowledge and attitudes in cancer pain. J Pain Symptom Manag. 1996;12(4):209-220.

165. Paice JA, Toy C, Shott S. Barriers to cancer pain relief: fear of tolerance and addiction. J Pain Symptom Manag. 1998;16(1):1-9.

166. Potter VT, Wiseman CE, Dunn SM, Boyle FM. Patient barriers to optimal cancer pain control. Psychooncology. 2003;12(2):153-160.

167. Riddell A, Fitch MI. Patients' knowledge of and attitudes toward the management of cancer pain. Oncol Nurs Forum. 1997;24(10): 1775-1784.

168. Ward SE, Carlson-Dakes K, Hughes SH, Kwekkeboom KL, Donovan HS. The impact on quality of life of patient-related barriers to pain management. Res Nurs Health. 1998;21(5):405-413.

169. Ward SE, Goldberg N, Miller-McCauley V, et al. Patient-related barriers to management of cancer pain. Pain. 1993;52(3):319-324.

170. Kroenke K, Theobald D, Wu J, Loza JK, Carpenter JS, Tu W. The association of depression and pain with health-related quality of life, disability, and health care use in cancer patients. J Pain Symptom Manag. 2010;40(3):327-341. 
171. Vallerand AH, Hasenau S, Templin T, Collins-Bohler D. Disparities between black and white patients with cancer pain: the effect of perception of control over pain. Pain Med. 2005;6(3):242-250.

172. Randall-David E, Wright J, Porterfield DS, Lesser G. Barriers to cancer pain management: home-health and hospice nurses and patients. Support Care Cancer. 2003;11(10):660-665.

173. Yates PM, Edwards HE, Nash RE, et al. Barriers to effective cancer pain management: a survey of hospitalized cancer patients in Australia. J Pain Symptom Manag. 2002;23(5):393-405.

174. Breitbart W, Passik S, McDonald MV, et al. Patient-related barriers to pain management in ambulatory AIDS patients. Pain. 1998;76(1-2):9-16

175. Fitzcharles MA, DaCosta D, Ware MA, Shir Y. Patient barriers to pain management may contribute to poor pain control in rheumatoid arthritis. J Pain. 2009;10(3):300-305.

176. The American Chronic Pain Association. The Myths of Pain Control; 2006. Available from: https://theacpa.org/uploads/documents/ chronicle_fall06_82806.pdf. Accessed June 2016.

177. Bistre S, Strauss Y. Errors in pain management: a Mexican perspective. $J$ Pain Palliat Care Pharmacother. 2012;26(3):266-270.

178. Holmes A, Christelis N, Arnold C. Depression and chronic pain. Med J Aust. 2013;199(Suppl 6):S17-S20.

179. Castro M, Quarantini LC, Daltro C, et al. Comorbid depression and anxiety symptoms in chronic pain patients and their impact on health-related quality of life. Arch Clin Psychiatry (São Paulo). 2011;38(4):126-129.

180. Covic T, Cumming SR, Pallant JF, et al. Depression and anxiety in patients with rheumatoid arthritis: prevalence rates based on a comparison of the Depression, Anxiety and Stress Scale (DASS) and the hospital, Anxiety and Depression Scale (HADS). BMC Psychiatry. 2012;12(6):1-10.

181. Galloway SK, Baker M, Giglio P, et al. Depression and anxiety symptoms relate to distinct components of pain experience among patients with breast cancer. Pain Res Treat. 2012;2012:851276.

182. Staiger TO, Gaster B, Sullivan MD, Deyo RA. Systematic review of antidepressants in the treatment of chronic low back pain. Spine. 2003;28(22):2540-2545.

183. Roditi D, Robinson ME. The role of psychological interventions in the management of patients with chronic pain. Psychol Res Behav Manag. 2011;4:41-49.

184. Turner JA, Chapman CR. Psychological interventions for chronic pain: a critical review. I. Relaxation training and biofeedback. Pain. 1982;12(1):1-21.

185. Turk DC, Melzack R. Handbook of Pain Assessment. New York, NY: Guilford Press; 2011.

186. Morón Merchante I, Pergolizzi JV, van de Laar M, et al. Tramadol/ paracetamol fixed-dose combination for chronic pain management in family practice: a clinical review. ISRN Family Med. 2013;2013:638469

187. Cruccu G, Truini A. Tools for assessing neuropathic pain. PLoS Med. 2009;6(4):e1000045.

188. Backonja MM, Attal N, Baron R, et al. Value of quantitative sensory testing in neurological and pain disorders. Pain. 2013;154(9):1807-1819.

189. Cruccu G, Anand P, Attal N, et al. EFNS guidelines on neuropathic pain assessment. Eur J Neurol. 2004;11(3):153-162.

190. Rolke R, Baron R, Maier C, et al. Quantitative sensory testing in the German Research Network on Neuropathic Pain (DFNS): standardized protocol and reference values. Pain. 2006;123(3):231-243.

191. Arendt-Nielsen L, Yarnitsky D. Experimental and clinical applications of quantitative sensory testing applied to skin, muscles and viscera. J Pain. 2009;10(6):556-572.

192. Lautenbacher S, Rollman GB, McCain G. Multi-method assessment of experimental and clinical pain in patients with fibromyalgia. Pain. 1994;59(1):45-53.

193. Wylde V, Palmer S, Learmonth ID, Dieppe P. Test-retest reliability of quantitative sensory testing in knee osteoarthritis and healthy participants. Osteoarthritis Cartilage. 2011;19(6):655-658.
194. Childs JD, Cleland JA, Elliott JM, et al. Neck pain: clinical practice guidelines linked to the International classification of functioning, disability, and health from the orthopaedic section of the American Physical Therapy Association. J Orthop Sports Phys Ther. 2008;38(9):A1-A34.

195. Lateef H, Patel D. What is the role of imaging in acute low back pain? Curr Rev Musculoskelet Med. 2009;2(2):69-73.

196. Cohen M, Jangro W. A clinical ethics approach to opioid treatment of chronic noncancer pain. AMA J Ethics. 2015;17(6):521-529.

197. Nurcan Ã̃̃, Sommer C. Neuropathic pain assessment - an overview of existing guidelines and discussion points for the future. Eur Neurol Rev. 2011;6(2):128-131.

198. Turk DC, Audette J, Levy RM, Mackey SC, Stanos S. Assessment and treatment of psychosocial comorbidities in patients with neuropathic pain. Mayo Clin Proc. 2010;85(3 suppl):S42-S50.

199. Heckman BD, Holroyd KA, Himawan L, et al. Do psychiatric comorbidities influence headache treatment outcomes? Results of a naturalistic longitudinal treatment study. Pain. 2009;146(1-2): $56-64$.

200. Leo RJ. Chronic pain and comorbid depression. Curr Treat Options Neurol. 2005;7(5):403-412.

201. Amarapurkar DN. Prescribing medications in patients with decompensated liver cirrhosis. Int J Hepatol. 2011;2011:519526.

202. Rifkin BS, Perazella MA. Analgesic therapy in patients with chronic kidney disease: a case-based approach. Hosp Physician. 2005;43:13-22.

203. Radner H, Ramiro S, van der Heijde DM, Landewe R, Buchbinder R, Aletaha D. How do gastrointestinal or liver comorbidities influence the choice of pain treatment in inflammatory arthritis? A Cochrane systematic review. J Rheumatol. 2012;90:74-80.

204. Billa G, Gabhane M, Biswas S. Practice of pain management by Indian healthcare practitioners: results of a paper based questionnaire survey. Pain Res Treat. 2015;2015:8.

205. Gatchel RJ, Peng YB, Peters ML, Fuchs PN, Turk DC. The biopsychosocial approach to chronic pain: scientific advances and future directions. Psychol Bull. 2007;133(4):581-624.

206. Vasudevan SV, Potts EE, Mehrotra C. Pain management in arthritis: evidence-based guidelines. Wis Med J. 2003;102(7):14-18.

207. Singh JA, Saag KG, Bridges SL, et al. 2015 American College of Rheumatology guideline for the treatment of rheumatoid arthritis. Arthritis Rheum. 2016;68(1):1-26.

208. Dworkin RH, O'Connor AB, Backonja M, et al. Pharmacologic management of neuropathic pain: evidence-based recommendations. Pain. 2007;132(3):237-251.

209. Dworkin RH, Backonja M, Rowbotham MC, et al. Advances in neuropathic pain: diagnosis, mechanisms, and treatment recommendations. Arch Neurol. 2003;60(11):1524-1534.

210. Van Seventer R, Bach FW, Toth CC, et al. Pregabalin in the treatment of post-traumatic peripheral neuropathic pain: a randomized doubleblind trial. Eur J Neurol. 2010;17(8):1082-1089.

211. Watson CPN, Moulin D, Watt-Watson J, Gordon A, Eisenhoffer J. Controlled-release oxycodone relieves neuropathic pain: a randomized controlled trial in painful diabetic neuropathy. Pain. 2003;105(1-2):71-78.

212. Eisenberg E, McNicol ED, Carr DB. Efficacy and safety of opioid agonists in the treatment of neuropathic pain of nonmalignant origin: systematic review and meta-analysis of randomized controlled trials. JAMA. 2005;293(24):3043-3052.

213. Smith HS. Opioids and neuropathic pain. Pain Physician. 2012; 15(3 Suppl):ES93-ES110.

214. Howard F. ACOG Practice Bulletin No. 51. Chronic pelvic pain. Obstet Gynecol. 2004;103(3):589-605.

215. Fall M, Baranowski AP, Elneil S, et al. EAU guidelines on chronic pelvic pain. Eur Urol. 2010;57:35-48.

216. Jarrell JF, Vilos GA, Allaire C. Consensus guidelines for the management of chronic pelvic pain. J Obstet Gynaecol Can. 2005;27(9): 869-887. 
217. Bernabei R, Gambassi G, Lapane K, et al. Management of pain in elderly patients with cancer. JAMA. 1998;279(23):1877-1882.

218. Cavalieri TA. Managing pain in geriatric patients. $J$ Am Osteopath Assoc. 2007; 107(Suppl 4):10-16.

219. McLachlan AJ, Bath S, Naganathan V, et al. Clinical pharmacology of analgesic medicines in older people: impact of frailty and cognitive impairment. Br J Clin Pharmacol. 2011;71(3):351-364.

220. Falzone E, Hoffmann C, Keita H. Postoperative analgesia in elderly patients. Drugs Aging. 2013;30(2):81-90.

221. Bressler HB, Keyes WJ, Rochon PA, Badley E. The prevalence of low back pain in the elderly: a systematic review of the literature. Spine. 1999;24(17):1813.

222. Forman WB. Opioid analgesic drugs in the elderly. Clin Geriatr Med. 1996;12(3):489-500.

223. WHO. WHO guidelines for the management of persistent pain in children with medical illnesses; 2012. Available from: http://apps. who.int/iris/bitstream/10665/44540/1/9789241548120_Guidelines. pdf. Accessed June 2016.

224. Bieri D, Reeve RA, Champion GD, Addicoat L, Ziegler JB. The Faces Pain Scale for the self-assessment of the severity of pain experienced by children: development, initial validation, and preliminary investigation for ratio scale properties. Pain. 1990;41(2):139-150.

225. Goodenough B, Addicoat L, Champion GD, et al. Pain in 4-to 6-yearold children receiving intramuscular injections: a comparison of the Faces Pain Scale with other self-report and behavioral measures. Clin J Pain. 1997;13(1):60-73.

226. Verghese ST, Hannallah RS. Acute pain management in children. J Pain Res. 2010;3:105-123.

227. Koren G, Florescu A, Costei AM, Boskovic R, Moretti ME. Nonsteroidal antiinflammatory drugs during third trimester and the risk of premature closure of the ductus arteriosus: a meta-analysis. Ann Pharmacother. 2006;40(5):824-829.

228. Schiff E, Mashiach $\mathrm{S}$. The use of low dose aspirin in pregnancy. $A m$ J Reprod Immunol. 1992;28(3-4):153-156.

229. Malhotra S, Khanna S. Safety of analgesics in pregnancy. Int J Obstet Gynaecol Res. 2016;3(1):208-212.

230. Doncaster and Bassetlaw Hospitals, NHS Foundation Trust. Analgesia in Patients with Impaired Renal Function - Formulary Guidance; 2014. Available from: https://usa1990fa.files.wordpress.com/2014/10/ analgesia-in-patients-with-impaired-renal-function.pdf. Accessed June 2016.
231. Sakata RK, Nunes MHG. Analgesics use for kidney failure. Revista Dor. 2014;15(3):224-229.

232. Pham P-CT, Toscano E, Pham P-MT, Pham P-AT, Pham SV, Pham P-TT. Pain management in patients with chronic kidney disease. NDT Plus. 2009;2(2):111-118.

233. Johnson SJ. Opioid safety in patients with renal or hepatic dysfunction. Pain Treat Topics. 2007;6:1.

234. Bosilkovska M, Walder B, Besson M, Daali Y, Desmeules J. Analgesics in patients with hepatic impairment. Drugs. 2012;72(12): $1645-1669$.

235. Imani F, Motavaf M, Safari S, Alavian SM. The therapeutic use of analgesics in patients with liver cirrhosis: a literature review and evidence-based recommendations. Hepat Mon. 2014;14(10):e23539.

236. Hamilton J, Goldberg E, Chopra S, Chief JTF, Runyon BA. Management of Pain in Patients with Advanced Chronic Liver Disease or Cirrhosis. Wolter Kluwer: Waltham, MA: 2012.

237. Benson GD, Koff RS, Tolman KG. The therapeutic use of acetaminophen in patients with liver disease. Am J Ther. 2005;12(2): 133-141.

238. Chandok N, Watt KDS. Pain management in the cirrhotic patient: the clinical challenge. Mayo Clin Proc. 2010;85(5):451-458.

239. McPherson ML Canaday BR, Heit HA, Rospond RM. A Pharmacist's Guide to the Clinical Assessment and Management of Pain. American Pharmacists Association; 2004. Available from: http://www.ulm. edu/ biglane/4058\%20Pain\%20-pharmacists-guide.pdf. Accessed June 2016.

240. Bell GM, Schnitzer TJ. Cox-2 inhibitors and other nonsteroidal antiinflammatory drugs in the treatment of pain in the elderly. Clin Geriatr Med. 2001;17(3):489-502.

241. Antman EM, Bennett JS, Daugherty A, Furberg C, Roberts H, Taubert KA. Use of nonsteroidal antiinflammatory drugs. An update for clinicians: a scientific statement from the American Heart Association. Circulation. 2007;115:1634-1642.

242. Dworkin RH, O'Connor AB, Audette J, et al. Recommendations for the pharmacological management of neuropathic pain: an overview and literature update. Mayo Clin Proc. 2010;85(3 suppl):S3-S14.

243. Cleeland C, Ryan K. Pain assessment: global use of the Brief Pain Inventory. Ann Acad Med Singapore. 1994;23(2):129-138.

244. Cleeland CS, Ryan K. The Brief Pain Inventory. Pain Research Group; 1991. Available from: http://sosmanuals.com/manuals/cae48184b7bae3b1d85105ea85375b60.pdf. Accessed June 2016. 


\section{Supplementary materials \\ Pain Assessment Scales}

1. Brief Pain Inventory (BPI)

Originally developed for assessment of pain in cancer patients, the BPI has been successfully used in a variety of clinical settings. ${ }^{1}$ In the BPI, severity of pain is measured across four grades, and the degree of interference of pain is evaluated across seven parameters: general activity, walking, work, mood, enjoyment of life, relationship with others and sleep. ${ }^{2}$ Several modified versions of the BPI have been developed to adapt to the requirements of the target population across different geographical settings. The reliability of the Hindi version of the BPI was demonstrated in a clinical trial in North India by Saxena et al. ${ }^{3}$

\section{McGill Pain Questionnaire (MPQ)}

Developed by Melzack and Torgerson in $1971,{ }^{4}$ the MPQ is a multidimensional pain assessment tool consisting of three major classes of word descriptors (total of 78 words) reflecting sensory, affective and evaluative components. It also contains a pain intensity scale ranging from one to five to rate the severity of the pain. ${ }^{5} \mathrm{MPQ}$ and the short-form MPQ (SF-MPQ) are valid and reliable tools to assess chronic pain, particularly cancer pain, in adults. ${ }^{6-9}$ The MPQ can also be used in the assessment of neuropathic and arthritic pain. ${ }^{10-12}$

\section{Visual Analog Scale (VAS)}

The VAS is a simple, easily administered, single-item tool to assess pain severity, especially in acute pain. ${ }^{13}$ VAS consists of a horizontal or vertical rating scale $(1-10 \mathrm{~cm})$ with verbal descriptors of "no pain" and "pain as bad as it could be." The patient is asked to mark the level of pain on the numerical scale of $1-10 \mathrm{~cm}$ (or 1-100 mm). Several studies have validated the use of VAS in acute and chronic pain. ${ }^{13-15}$

\section{Numerical Rating Scale (NRS)}

The NRS consists of a numerical scale similar to the VAS, however, with numbers marked from one to ten, ranging from "no pain" to "worst pain imaginable". The NRS is easy to administer via paper-and-pencil, telephone, fax or any computerized system and has demonstrated superiority over the VAS across different studies, ${ }^{16,17}$ especially in illiterate or elderly populations. ${ }^{18-20}$

\section{Verbal Rating Scale (VRS)}

The VRS scale is composed of a series of adjectives along with numbers to best describe the intensity of the pain. VRS has been reported to be well correlated with the VAS, in terms of simplicity and reliability. ${ }^{21,22}$ However, the VRS scale has been found to be less sensitive to changes in pain intensity and is considered highly subjective..$^{22-24}$

\section{Faces Pain Scale (FPS)}

For the self-reporting of pain severity in children, elderly and other special populations, FPS may be used. In this scale, pain is graded by means of facial expressions. FPS and the revised FPS have demonstrated reliability in predicting the severity of pain in children aged $4-8$ years and in patients with cognitive impairment. ${ }^{25-28}$

Table SI Treatment recommendations

\begin{tabular}{|c|c|c|}
\hline Type of pain & First-line therapy & Second-line therapy \\
\hline Diabetic neuropathy & $\begin{array}{l}\text { Gabapentin, pregabalin, tricyclic antidepressants } \\
\text { (amitriptyline, imipramine, desipramine) }[\mathrm{A}]\end{array}$ & Opioids (oxycodone, tramadol) [A] \\
\hline Postherpetic neuralgia & $\begin{array}{l}\text { Gabapentin, pregabalin, nortriptyline, amitriptyline, topical } \\
\text { capsaicin, topical lidocaine }[\mathrm{A}]\end{array}$ & Tramadol, oxycodone $[\mathrm{A}]$ \\
\hline Fibromyalgia & Amitriptyline, pregabalin $[\mathrm{A}]$ & Duloxetine $[\mathrm{B}]$ \\
\hline Trigeminal neuralgia & Carbamazepine $[\mathrm{A}]$ & Baclofen, lamotrigine, gamma-knife surgery $[\mathrm{B}]$ \\
\hline Low-back pain & $\begin{array}{l}\text { NSAIDs (ibuprofen, diclofenac) [A], opioids (tramadol, } \\
\text { codeine) [B] }\end{array}$ & $\begin{array}{l}\text { Strong opioids (morphine, fentanyl) }[\mathrm{A}] \text {, antidepressants } \\
\text { (amitriptyline, nortriptyline) }[\mathrm{A}] \text {, anticonvulsants (gabapentin, } \\
\text { pregabalin) }[\mathrm{C}]\end{array}$ \\
\hline Neck pain & Physiotherapy, exercise, acetaminophen, NSAIDs [A] & $\begin{array}{l}\text { Opioids, anticonvulsants, antidepressants, muscle relaxants, } \\
\text { acupuncture, single-point injections }[B, C]\end{array}$ \\
\hline Migraine headache & $\begin{array}{l}\text { Sumatriptan, zolmitriptan [A], NSAIDs (ibuprofen) }[\mathrm{A}] \\
\text { antiemetics (prochlorperazine, chlorpromazine) }[\mathrm{A}]\end{array}$ & $\begin{array}{l}\text { Ergotamine, dihydroergotamine }[\mathrm{B}] \text {, opioids (morphine, } \\
\text { tramadol) }[\mathrm{B}]\end{array}$ \\
\hline $\begin{array}{l}\text { Tension-type or cluster } \\
\text { headache }\end{array}$ & $\begin{array}{l}\text { Acetaminophen, NSAIDs (ibuprofen, ketoprofen, diclofenac, } \\
\text { naproxen) [A] }\end{array}$ & $\begin{array}{l}\text { Acetaminophen-caffeine }[A], \text { NSAID-caffeine combination } \\
{[A] \text {, relaxation and acupuncture }[C]}\end{array}$ \\
\hline Arthritic pain & $\begin{array}{l}\text { Acetaminophen }[\mathrm{A}], \text { NSAIDs }[\mathrm{A}] \text {, weak opioids (tramadol, } \\
\text { codeine) }[\mathrm{A}]\end{array}$ & $\begin{array}{l}\text { Strong opioids (morphine, oxycodone) [B], antidepressants } \\
\text { (amitriptyline, nortriptyline) [C] }\end{array}$ \\
\hline Cancer pain & Weak opioids (codeine, tramadol) with/without NSAIDs [A] & Strong opioids (morphine, oxycodone, fentanyl) [A] \\
\hline
\end{tabular}

Note: Recommendations were graded by an expert panel based on available evidence. Grade A: based on evidence Level I. Grade B: based on evidence Level 2 or extrapolated from Level I. Grade C: based on evidence Level 3 or extrapolated from Level I and 2.

Abbreviation: NSAIDs, nonsteroidal anti-inflammatory drugs. 
7. Disease-specific assessment scales

Due to the methodological problems faced during the assessment of pain using standard tools, ${ }^{29}$ disease-specific pain measurement questionnaires have been developed with an aim to correctly capture the nature and severity of pain in different pathophysiological conditions. ${ }^{30}$ Use of Neuropathic Pain Scale (NPS), Neuropathic Pain Questionnaire (NPQ) and Leeds Assessment of Neuropathic Symptoms and Signs (LANSS) Pain Scale is recommended to differentiate between nociceptive and neuropathic pain (A).

8. Cognitive and behavioral assessment scales

Pain perception is greatly influenced by the psychological and emotional status of the patient. Chronic pain may induce notable changes in the behavior, cognition and social abilities of a person. Pain is also accompanied by a state of fear, anxiety, depression and negative beliefs. These psychological traits may serve as important predictors of chronic pain and disability and may determine treatment outcomes. Therefore, a comprehensive pain management program should also involve psychological, cognitive and behavioral assessment of the patient. For this purpose, tools such as Pain Beliefs and Perceptions Inventory (PBPI), Pain Anxiety Symptoms Scale (PASS), Cognitive Evaluation Questionnaire and the Patient Attitude Questionnaire (PAQ) may be used.

9. Assessment in elderly or cognitively impaired patients Patients' self-reports of pain have been proven to be more reliable tools for accurate diagnosis of pain and treatment of pain. However, obtaining detailed self-reports in both patients with cognitive impairment and the elderly can prove to be a major challenge and, therefore, requires the use of pain assessment tools that are relatively easy and adequately describe the pain experience. ${ }^{31}$ For cognitively sound older adults, the VRS, NRS or FPS may be easy and reliable to use (A), whereas in elderly with symptoms of dementia or cognitive impairment, ${ }^{32}$ the Abbey's Pain Scale, Pain Assessment in Advanced Dementia Scale (PAINAD) and Pain Assessment for the Dementing Elderly (PADE) have demonstrated reliability (A). ${ }^{33-35}$

\section{Disease-specific treatment recommendations \\ Low-back pain (LBP)}

1. Classification

- LBP is localized to the lumbar vertebrae (L1-15) just above the gluteus muscle.
- LBP can be classified by duration as acute ( $<6$ weeks), subacute (6-12 weeks) and chronic ( $>12$ weeks).

- LBP may be classified by cause as mechanical (strains/ sprains or fractures), nonmechanical (tumors) and referred pain (kidney or gall stones or pain in nearby tissue). ${ }^{36}$

- LBP is classified by mechanism or "diagnostic triage" into serious spinal pathology (accompanied by "red flags"), nerve root pain/radicular pain and nonspecific LBP.

2. Diagnosis

- Use diagnostic methods such as physical examination, X-rays, ultrasonography, computed tomography (CT) scans, magnetic resonance imaging (MRI), diskography, bone scans and blood tests (B). ${ }^{37-39}$

- Identify "red flags", which are signs/symptoms that are unlikely to be observed in normal LBP and generally indicate involvement of serious pathology. Identifying the red flags may help diagnose underlying chronic conditions, such as cancer (C).

- Identify “yellow flags', which represent the psychosocial barriers that may influence the subjective response to pain and which may delay recovery or indicate the risk of chronification or disability (C).

3. Treatment

- Initiate treatment with acetaminophen and mild NSAIDs (ibuprofen, diclofenac) as first-line therapy (A)..$^{40,41}$

- Second-line therapy should typically involve a combination of NSAIDs and mild opioids (codeine, tramadol) (A), ${ }^{41,42}$ followed by moderate-to-strong opioids (morphine, fentanyl) in severe pain. ${ }^{42,43}$

- Third-line therapy should be initiated in case a central origin is suspected or if pain significantly affects the physical, mental and social behavior of patients; it may include anticonvulsants (gabapentin, pregabalin), ${ }^{44}$ sedatives (benzodiazepines) and antidepressants (amitriptyline, nortriptyline) (A). ${ }^{45-47}$

\section{Neck pain}

1. Classification

- Neck pain can be classified into four classes according to the impact of pain on body function and movement, as follows:

- Pain with mobility deficits

- Pain with headache

- Pain with radiating pain 
- Pain with impaired movement.

- Based on the causative mechanism, neck pain may be classified as follows:

- Axial neck pain caused due to incorrect posture, physical stress or fatigue

- Whiplash-associated disorder (WAD) due to pain in the muscles, joints, tendons and ligaments due to injuries or impact

- Cervical radiculopathy and myelopathy due to changes to the sensory/motor function of cervical nerves or compression of spinal cord.

2. Diagnosis

- Diagnosis should be preceded by careful evaluation of patient, the nature and extent of pain and any additional symptoms such as headaches, nausea, vomiting, vertigo or other distress (C). ${ }^{48}$

- Symptom assessment may help in differentiating different types of neck pains. Sharp, shooting or tingling pain may indicate a radicular origin, whereas dull, aching pain accompanied with soreness or tenderness may point toward axial pain $(\mathrm{C})$.

- Physical examination and self-report questionnaires are more valid assessment tools and should be preferred over diagnostic tests such as imaging, electrophysiology or blood tests, which have failed to demonstrate reliability $(\mathrm{C})$.

- Identify the "red flags", which may include trauma, infections, history of pain, malignancy or major trauma, in addition to weight loss, chest pain, nausea, vomiting or fever (C). ${ }^{49}$

3. Treatment

- Exercise and physiotherapy are the most effective interventional methods with proven efficacy in neck pain (A). ${ }^{50-53}$

- Analgesics such as acetaminophen and NSAIDs may be used for acute pain, and weak opioids may be used for chronic episodes, as first-line therapies (A). ${ }^{49}$

- Antidepressants, muscle relaxants and strong opioids may be reserved for refractory cases or after failure of other interventional methods $(\mathrm{C}){ }^{48}$

\section{Headache}

1. Classification

- According to the International Headache Society, primary headaches can be classified into migraine headaches, cluster headaches and tension-type headaches. Migraine headaches result from migraine disorders, which are further categorized as migraine with aura, migraine without aura, childhood migraine or retinal migraine depending upon the presentation. ${ }^{54-56}$

- Secondary headaches may be caused due to an underlying disorder such as tumors.

2. Diagnosis

- Preliminary diagnosis can be performed through symptom assessment and detailed evaluation of patient profile and history or presence of underlying disorders.

- A typical migraine attack is triggered by physical activity and may be suspected if symptoms involve severe pulsating or throbbing headache on one or both sides of the head, sometimes accompanied by visual aura, sensitivity to light, nausea or vomiting. Frequently occurring migraine attacks ( $\geq 15$ days per month for $>3$ months) despite continuing medication may be regarded as chronic migraine; the duration of headache may be 4-72 hours.

- Tension-type headaches, also known as ordinary headaches, may be triggered by stress. The pain is usually bilateral, with pressing/tightening quality and is not usually accompanied by nausea, vomiting or light sensitivity. Persistent tension-type headache may indicate the presence of serious underlying disorders. These headaches may last from a few minutes to days (up to 7 days).

- Cluster headaches usually involve severe unilateral pain around the eyes (orbital pain), forehead or sides of the head (temporal pain). These headaches may last for 10 minutes to 4 hours.

- Diagnosis by neuroimaging techniques should be reserved for patients who have persistent pain lasting 6-month duration, often in the absence of migraine and accompanied by neurologic symptoms such as confusion, visual problems and hallucinations; also to be used in the case of patients with history of such disorders in the past $(\mathrm{B}){ }^{57}$

3. Treatment

- Migraine headache: begin initial treatment with oral triptans (sumatriptan or zolmitriptan), followed by the antiemetics prochlorperazine or chlorpromazine in case of nausea and vomiting (A); opioids and antidepressants may be considered as second-line therapy. In children, initial treatment may be initiated with acetaminophen and ibuprofen, followed by sumatriptan nasal spray or oral triptans (A). ${ }^{58-68}$

- Cluster and tension-type headaches: treatment for cluster and tension-type headaches should consist 
of acetaminophen, low-dose NSAIDs (ibuprofen, naproxen and diclofenac), followed by an NSAIDcaffeine or acetaminophen-caffeine combination as second-line therapy (A). ${ }^{69-72}$

\section{Arthritic pain}

\section{Classification}

- Although arthritic pain involves both rheumatoid arthritis and osteoarthritis, primarily it can be classified as inflammatory arthritis, noninflammatory arthritis or arthralgia. Inflammatory pain involves the inflammation of the joints, synovial cavity or synovium. Noninflammatory arthritic pain may result from altered joint mechanics, while arthralgia represents joint tenderness in absence of inflammation, usually resulting from an underlying condition such as fibromyalgia. ${ }^{73}$

\section{Diagnosis}

- Carefully observe symptoms of swelling, tenderness, redness and stiffness, as well as checking joint movement, wrist movement, rotation, movement or function $(\mathrm{B}) .^{73}$

- The diagnosis may be confirmed using bone aspiration tests and imaging tests (B).

\section{Treatment}

- First-line therapy should consist of acetaminophen and oral or topical NSAIDs (ibuprofen, diclofenac or naproxen) (A). ${ }^{73-75}$

- Second-line therapy with opioids (tramadol, morphine and oxycodone) should be considered only if the patient is unable to tolerate NSAIDs or if pain persists despite NSAID medication (A).

\section{References}

1. Cleeland C, Ryan K. Pain assessment: global use of the Brief Pain Inventory. Ann Acad Med Singapore. 1994;23(2):129-138.

2. Cleeland CS, Ryan K. The Brief Pain Inventory. Pain Research Group; 1991. Available from: http://sosmanuals.com/manuals/cae48184b7bae3b1d85105ea85375b60.pdf. Accessed June 2016.

3. Saxena A, Mendoza T, Cleeland CS. The assessment of cancer pain in north India: the validation of the Hindi Brief Pain Inventory - BPI-H. J Pain Symptom Manag. 1999;17(1):27-41.

4. Melzack R, Togerson WS. On the language of pain. Anesthesiology. 1971;34(1):50-59.

5. Melzack R. The McGill Pain Questionnaire: major properties and scoring methods. Pain. 1975;1(3):277-299.

6. Ngamkham S, Vincent C, Finnegan L, Holden JE, Wang ZJ, Wilkie DJ. The McGill pain questionnaire as a multidimensional measure in people with cancer: an integrative review. Pain Manag Nurs. 2012;13(1):27-51.

7. Dudgeon D, Raubertas RF, Rosenthal SN. The short-form McGill pain questionnaire in chronic cancer pain. J Pain Symptom Manag. 1993;8(4):191-195.

8. Graham C, Bond SS, Gerkovich MM, Cook MR. Use of the McGill pain questionnaire in the assessment of cancer pain: replicability and consistency. Pain. 1980;8(3):377-387.
9. Kremer EF, Atkinson JH, Ignelzi RJ. Pain measurement: the affective dimensional measure of the McGill Pain questionnaire with a cancer pain population. Pain. 1982;12(2):153-163.

10. Lovejoy TI, Turk DC, Morasco BJ. Evaluation of the psychometric properties of the revised Short-Form McGill Pain Questionnaire (SFMPQ-2). J Pain. 2012;13(12):1250-1257.

11. Burckhardt CS, Jones KD. Adult measures of pain: The McGill Pain Questionnaire (MPQ), Rheumatoid Arthritis Pain Scale (RAPS), Short-Form McGill Pain Questionnaire (SF-MPQ), Verbal Descriptive Scale (VDS), Visual Analog Scale (VAS), and West Haven-Yale Multidisciplinary Pain Inventory (WHYMPI). Arthritis Care Res. 2003;49(S5):S96-S104.

12. Kachooei AR, Ebrahimzadeh MH, Erfani-Sayyar R, Salehi M, Salimi E, Razi S. Short Form-McGill Pain Questionnaire-2 (SF-MPQ-2): a cross-cultural adaptation and validation study of the Persian version in patients with knee osteoarthritis. Arch Bone Jt Surg. 2015;3(1):45-50.

13. Bijur PE, Silver W, Gallagher EJ. Reliability of the visual analog scale for measurement of acute pain. Acad Emerg Med. 2001;8(12):1153-1157.

14. Seymour R. The use of pain scales in assessing the efficacy of analgesics in post-operative dental pain. Eur J Clin Pharmacol. 1982;23(5):441-444.

15. Price DD, McGrath PA, Rafii A, Buckingham B. The validation of visual analogue scales as ratio scale measures for chronic and experimental pain. Pain. 1983;17(1):45-56.

16. Paice JA, Cohen FL. Validity of a verbally administered numeric rating scale to measure cancer pain intensity. Cancer Nurs. 1997;20(2):88-93.

17. Jensen MP, Karoly P, Braver S. The measurement of clinical pain intensity: a comparison of six methods. Pain. 1986;27(1):117-126.

18. Ferraz MB, Quaresma M, Aquino L, Atra E, Tugwell P, Goldsmith C. Reliability of pain scales in the assessment of literate and illiterate patients with rheumatoid arthritis. JRheumatol. 1990;17(8):1022-1024.

19. Hjermstad MJ, Fayers PM, Haugen DF, et al. Studies comparing Numerical Rating Scales, Verbal Rating Scales, and Visual Analogue Scales for assessment of pain intensity in adults: a systematic literature review. J Pain Symptom Manag. 2011;41(6):1073-1093.

20. Briggs M, Closs JS. A descriptive study of the use of visual analogue scales and verbal rating scales for the assessment of postoperative pain in orthopedic patients. J Pain Symptom Manag. 1999;18(6):438-446.

21. Littman GS, Walker BR, Schneider BE. Reassessment of verbal and visual analog ratings in analgesic studies. Clin Pharmacol Ther. 1985;38(1):16-23.

22. Holdgate A, Asha S, Craig J, Thompson J. Comparison of a verbal numeric rating scale with the visual analogue scale for the measurement of acute pain. Emerg Med (Fremantle). 2003;15(5-6):441-446.

23. Aicher B, Peil H, Peil B, Diener H. Pain measurement: Visual Analogue Scale (VAS) and Verbal Rating Scale (VRS) in clinical trials with OTC analgesics in headache. Cephalalgia. 2012;32(3):185-197.

24. Langley G, Sheppeard H. Problems associated with pain measurement in arthritis: comparison of the visual analogue and verbal rating scales. Clin Exp Rheumatol. 1983;2(3):231-234.

25. Bieri D, Reeve RA, Champion GD, Addicoat L, Ziegler JB. The Faces Pain Scale for the self-assessment of the severity of pain experienced by children: development, initial validation, and preliminary investigation for ratio scale properties. Pain. 1990;41(2):139-150.

26. Goodenough B, Addicoat L, Champion GD, et al. Pain in 4-to 6-year-old children receiving intramuscular injections: a comparison of the Faces Pain Scale with other self-report and behavioral measures. Clin J Pain. 1997;13(1):60-73.

27. Ware LJ, Epps CD, Herr K, Packard A. Evaluation of the revised faces pain scale, verbal descriptor scale, numeric rating scale, and Iowa pain thermometer in older minority adults. Pain Manag Nurs. 2006;7(3):117-125.

28. Hicks CL, von Baeyer CL, Spafford PA, van Korlaar I, Goodenough B. The Faces Pain Scale-Revised: toward a common metric in pediatric pain measurement. Pain. 2001;93(2):173-183.

29. Ohnhaus EE, Adler R. Methodological problems in the measurement of pain: a comparison between the verbal rating scale and the visual analogue scale. Pain. 1975;1(4):379-384.

30. Salaffi F, Ciapetti A, Carotti M. Pain assessment strategies in patients with musculoskeletal conditions. Reumatismo. 2012;64(4):216-229. 
31. Herr K, Coyne PJ, McCaffery M, Manworren R, Merkel S. Pain assessment in the patient unable to self-report: position statement with clinical practice recommendations. Pain Manag Nurs. 2011;12(4):230-250.

32. Herr K, Bjoro K, Decker S. Tools for assessment of pain in nonverbal older adults with dementia: a state-of-the-science review. J Pain Symptom Manag. 2006;31(2):170-192.

33. Abbey J, Piller N, De Bellis A, et al. The Abbey pain scale: a 1-minute numerical indicator for people with end-stage dementia. Int J Palliat Nurs. 2004;10(1):6-13.

34. Warden V, Hurley AC, Volicer L. Development and psychometric evaluation of the Pain Assessment in Advanced Dementia (PAINAD) Scale. J Am Med Dir Assoc. 2003;4(1):9-15.

35. Villanueva MR, Smith TL, Erickson JS, Lee AC, Singer CM. Pain assessment for the dementing elderly (PADE): reliability and validity of a new measure. J Am Med Dir Assoc. 2003;4(1):1-8.

36. Bogduk N. Evidence-based clinical guidelines for the management of acute low back pain. Australian faculty of musculoskeleltal medicine; 1999.

37. Lateef H, Patel D. What is the role of imaging in acute low back pain? Curr Rev Musculoskelet Med. 2009;2(2):69-73.

38. Jarvik JG, Deyo RA. Diagnostic evaluation of low back pain with emphasis on imaging. Ann Intern Med. 2002;137(7):586-597.

39. O'Sullivan P. Diagnosis, classification management of chronic low back pain. Available from: http://www.smly.fi/@Bin/172109/lumbopelvic_workshoplevi07handouts.pdf. Accessed June 2016.

40. Van Tulder MW, Scholten RJ, Koes BW, Deyo RA. Nonsteroidal antiinflammatory drugs for low back pain: a systematic review within the framework of the Cochrane Collaboration Back Review Group. Spine. 2000;25(19):2501-2513.

41. Ruoff GE, Rosenthal N, Jordan D, Karim R, Kamin M; Protocol CAPSS-112 Study Group. Tramadol/Acetaminophen combination tablets for the treatment of chronic lower back pain: a multicenter, randomized, double-blind, placebo-controlled outpatient study. Clin Ther. 2003;25(4):1123-1141.

42. Schnitzer TJ, Gray WL, Paster RZ, Kamin M. Efficacy of tramadol in treatment of chronic low back pain. J Rheumatol. 2000;27(3):772-778.

43. Allan L, Richarz U, Simpson K, Slappendel R. Transdermal fentanyl versus sustained release oral morphine in strong-opioid naïve patients with chronic low back pain. Spine. 2005;30(22):2484-2490.

44. Moore RA, Straube S, Wiffen PJ, Derry S, McQuay HJ. Pregabalin for acute and chronic pain in adults. Cochrane Database Syst Rev. 2009;(3):CD007076.

45. Straube A, Aicher B, Fiebich BL, Haag G. Combined analgesics in (headache) pain therapy: shotgun approach or precise multi-target therapeutics? BMC Neurol. 2011;11(43):1-15.

46. Stein D, Peri T, Edelstein E, Elizur A, Floman Y. The efficacy of amitriptyline and acetaminophen in the management of acute low back pain. Psychosomatics. 1996;37(1):63-70.

47. Pilowsky I, Hallett EC, Bassett DL, Thomas PG, Penhall RK. A controlled study of amitriptyline in the treatment of chronic pain. Pain 1982;14(2):169-179

48. Childs JD, Cleland JA, Elliott JM, et al. Neck pain: clinical practice guidelines linked to the International classification of functioning, disability, and health from the orthopaedic section of the American Physical Therapy Association. J Orthop Sports Phys Ther. 2008;38(9):A1-A34.

49. Douglass AB, Bope ET. Evaluation and treatment of posterior neck pain in family practice. J Am Board Fam Pract. 2004;17(Suppl):S13-S22.

50. Fortier MA, Anderson CT, Kain ZN. Ethnicity matters in the assessment and treatment of children's pain. Pediatrics. 2009;124(1):378-380.

51. Campbell CM, Edwards RR. Ethnic differences in pain and pain management. Pain Manag. 2012;2(3):219-230.

52. Callister LC. Cultural influences on pain perceptions and behaviors. Home Health Care Manag Pract. 2003;15(3):207-211.

53. Shipton E. The pain experience and sociocultural factors. New Zealand Med J. 2013;126(1370):7-9.

54. Barnes TR. A rating scale for drug-induced akathisia. Br J Psychiatry. 1989;154(5):672-676.

55. Simpson GM, Angus JW. A rating scale for extrapyramidal side effects. Acta Psychiatr Scand. 1970;45(S212):11-19.
56. Kay SR, FiszbeinL A, Opler L. The positive and negative syndrome scale (PANSS) for schizophrenia. Schizophr Bull. 1987;13(2):261-276.

57. Evans RW, Rozen TD, Adelman JU. Neuroimaging and other diagnostic testing in headache. Wolff's Headache and Other Head Pain. 7th ed. Silberstein SD, Lipton RB, Dalessio DJ, editors. New York, NY: Oxford University Press; 2001:27-49.

58. Ahonen K, Hämäläinen ML, Rantala H, Hoppu K. Nasal sumatriptan is effective in treatment of migraine attacks in children: a randomized trial. Neurology. 2004;62(6):883-887.

59. Brandes JL, Kudrow D, Stark SR, et al. Sumatriptan-naproxen for acute treatment of migraine: a randomized trial. JAMA. 2007;297(13): 1443-1454

60. Brenner M, Lewis D. The treatment of migraine headaches in children and adolescents. J Pediatr Pharmacol Ther. 2008;13(1):17-24.

61. Colman I, Brown MD, Innes GD, Grafstein E, Roberts TE, Rowe BH. Parenteral dihydroergotamine for acute migraine headache: a systematic review of the literature. Ann Emerg Med. 2005;45(4):393-401.

62. Engindeniz Z, Demircan C, Karli N, et al. Intramuscular tramadol vs. diclofenac sodium for the treatment of acute migraine attacks in emergency department: a prospective, randomised, double-blind study. J Headache Pain. 2005;6(3):143-148.

63. Goldstein J, Silberstein SD, Saper JR, Ryan RE, Lipton RB. Acetaminophen, aspirin, and caffeine in combination versus ibuprofen for acute migraine: results from a multicenter, double-blind, randomized, parallel-group, single-dose, placebo-controlled study. Headache. 2006;46(3):444-453.

64. Hamalainen ML, Hoppu K, Valkeila E, Santavuori P. Ibuprofen or acetaminophen for the acute treatment of migraine in children a doubleblind, randomized, placebo-controlled, crossover study. Neurology. 1997;48(1):103-107.

65. Lewis D, Ashwal S, Hershey AO, Hirtz D, Yonker M, Silberstein S. Practice parameter: pharmacological treatment of migraine headache in children and adolescents Report of the American Academy of Neurology Quality Standards Subcommittee and the Practice Committee of the Child Neurology Society. Neurology. 2004;63(12):2215-2224.

66. Prior MJ, Codispoti JR, Fu M. A randomized, placebo-controlled trial of acetaminophen for treatment of migraine headache. Headache. 2010;50(5):819-833.

67. Silberstein SD, Consortium UH. Practice parameter: evidence-based guidelines for migraine headache (an evidence-based review) Report of the Quality Standards Subcommittee of the American Academy of Neurology. Neurology. 2000;55(6):754-762.

68. Winner P, Rothner AD, Saper J, et al. A randomized, double-blind, placebo-controlled study of sumatriptan nasal spray in the treatment of acute migraine in adolescents. Pediatrics. 2000;106(5):989-997.

69. Holmes A, Christelis N, Arnold C. Depression and chronic pain. Med J Aust. 2013;199(Suppl 6):S17-S20.

70. Castro M, Quarantini LC, Daltro C, et al. Comorbid depression and anxiety symptoms in chronic pain patients and their impact on health-related quality of life. Arch Clin Psychiatry (São Paulo). 2011;38:126-129.

71. Covic T, Cumming SR, Pallant JF, et al. Depression and anxiety in patients with rheumatoid arthritis: prevalence rates based on a comparison of the Depression, Anxiety and Stress Scale (DASS) and the hospital, Anxiety and Depression Scale (HADS). BMC Psychiatry. 2012;12:1-10.

72. Galloway SK, Baker M, Giglio P, et al. Depression and anxiety symptoms relate to distinct components of pain experience among patients with breast cancer. Pain Res Treat. 2012;2012:851276.

73. Jordan K, Arden N, Doherty M, et al. EULAR Recommendations 2003: an evidence based approach to the management of knee osteoarthritis: report of a Task Force of the Standing Committee for International Clinical Studies Including Therapeutic Trials (ESCISIT). Ann Rheum Dis. 2003;62(12):1145-1155.

74. Emery P, Zeidler H, Kvien TK, et al. Celecoxib versus diclofenac in long-term management of rheumatoid arthritis: randomised doubleblind comparison. Lancet. 1999;354(9196):2106-2111.

75. Lin J, Zhang W, Jones A, Doherty M. Efficacy of topical non-steroidal anti-inflammatory drugs in the treatment of osteoarthritis: meta-analysis of randomised controlled trials. BMJ. 2004;329(7461):324. 
The Journal of Pain Research is an international, peer reviewed, open access, online journal that welcomes laboratory and clinical findings in the fields of pain research and the prevention and management of pain. Original research, reviews, symposium reports, hypothesis formation and commentaries are all considered for publication.

Submit your manuscript here: https://www.dovepress.com/journal-of-pain-research-journal

The manuscript management system is completely online and includes a very quick and fair peer-review system, which is all easy to use. Visit http://www.dovepress.com/testimonials.php to read real quotes from published authors. 